Pontifícia UnIVERSIDADE CATÓLICA do RIO DE JANEIRO

\title{
ATITUDE E PERCEPÇÃO DO CONSUMIDOR SOBRE O POSICIONAMENTO DAS EMPRESAS DIRECIONADO AO PÚBLICO \\ LGBTQI+
}

\section{MATHEUS BARBOSA RIBEIRO}

Trabalho de Conclusão de Curso

CENTRO DE CIÊNCIAS SOCIAIS - CCS

Departamento de AdMINISTRAÇÃo

Graduação em Administração de Empresas 
Matheus Barbosa Ribeiro

Atitude e percepção do consumidor sobre 0 posicionamento das empresas direcionadas ao público LGBTQI+

Trabalho de Conclusão de Curso

Trabalho de Conclusão de Curso, apresentado ao programa de graduação em Administração da PUC-Rio como requisito parcial para a obtenção do título de graduação em Administração.

Orientador(a): Barbara Pagliari Levy

Rio de Janeiro, dezembro de 2019 


\section{Agradecimentos}

Em primeiro lugar gostaria de agradecer a minha família, por ter me incentivado e motivado a seguir e conquistar os meus objetivos. Sou grato por toda confiança depositada e por todos os ensinamentos. Em especial gostaria de destacar a minha tia Ivoneide Rufino, que hoje não se faz presente entre nós.

Em segundo lugar quero agradecer a minha orientadora Barbara Levy, por toda sua dedicação, instrução e paciência, sem sua ajuda e confiança não seria possível realizar esse estudo. Além disso, gostaria de destacar o quão grato sou por me permitir desenvolver este estudo sobre um tema tão delicado como este e importante para mim.

Quero agradecer também aos meus amigos que foram peças essenciais para a construção desse estudo e, em toda minha trajetória acadêmica, aqui deixo registrado toda minha gratidão à Brenda Pravato, Luisa Radaic, Gabriela Fonseca e Wallace Cordeiro. Além disso, destaco Urias Martins e Pedro Marzullo por me auxiliarem na correção de texto e André Amorim por me acompanhar na Parada do Orgulho LGBTQI+ de São Paulo, para realizar as entrevistas da primeira etapa desse trabalho. Destaco também, Paula Lom, Patrícia Hornick, Victor Wernerck, Lucas Wolfgang e Marcus Vinicius, por todo suporte e apoio durante essa jornada.

Por último, quero agradecer a todos que colaboraram para a construção desse estudo diretamente ou indiretamente. Sou grato por ter tido ao meu lado pessoas que me inspiraram e me confortaram durante a realização dessa etapa final da graduação.

"A vida é som que vem da terra, que eu não sei dizer" - Somos som (LOM PAULA, 2019) 


\section{Resumo}

Ribeiro, Matheus. Atitude e percepção do consumidor sobre o posicionamento das marcas direcionadas ao público LGBTQI+. Rio de Janeiro, 2019. 48 p. Trabalho de Conclusão de Curso - Departamento de Administração. Pontifícia Universidade Católica do Rio de Janeiro.

O estudo tem como objetivo compreender a atitude e percepção dos consumidores que definem sua orientação sexual como lésbicas, gays, bissexuais, transexuais/transgêneros, queer e intersex (LGBTQI+), sobre o posicionamento das marcas que estão desenvolvendo o marketing de causa, com o foco na comunidade. O alvo principal do estudo, está concentrado na interpretação do consumidor a respeito das ações de marketing com abordagem LGBTQI+, em especial o envolvimento das empresas com a Parada do Orgulho LGBTQI+ de São Paulo, 2019.

Palavras-chave

LGBT, LGBTQI+, marketing social, subcultura, pride, pink money

\section{Abstract}

Ribeiro, Matheus. Consumer Attitude and Perception of Public-Targeted Brand Positioning LGBTQI +. Rio de Janeiro, 2019. 48 p. Course Conclusion Paper - Department of Administration. Pontifical Catholic University of Rio de Janeiro.

The study aims to understand the attitude and perception of consumers who define their sexual orientation as lesbian, gay, bisexual, transgender / transgender, queer and intersex (LGBTQI +), about the positioning of brands that are developing cause marketing, with focus on the community. The main goal of the study is to focus on consumer interpretation of LGBTQI + marketing actions, especially the involvement of companies with the LGBTQI + Pride Parade in São Paulo, 2019.

\section{Key-words}

LGBT, LGBTQI+, social marketing, subculture, pride, pink money 


\section{Sumário}

1 Introdução 1

1.1. Objetivo principal 3

1.2. Delimitação do estudo 3

1.3. Relevância do estudo 4

2 Referencial teórico 5

2.1. Comportamento do Consumidor 5

2.1.1. Percepção do consumidor 6

$\begin{array}{ll}\text { 2.1.2. Cultura } & 7\end{array}$

2.1.3. Subcultura 8

2.1.4. Atitude do consumidor 9

2.1.5. Influência no processo de compra 10

$\begin{array}{ll}\text { 2.2. Posicionamento de marca } & 10\end{array}$

2.3. Relacionamento com os clientes 12

$\begin{array}{ll}\text { 2.3.1. Marketing de causa } & 13\end{array}$

3 Métodos e procedimentos de coleta e de análise de dados do estudo 15

$\begin{array}{ll}\text { 3.1. Etapas de coleta de dados } & 15\end{array}$

3.2. Fontes de informação selecionadas para coleta de dados no estudo

3.3. Procedimentos e instrumentos de coleta de dados utilizados no estudo

3.4. Formas de tratamento e análise dos dados coletados para o estudo18

3.5. Limitações do Estudo

4 Apresentação e análise dos resultados 20

4.1. Pink Money 20

4.2. A Envolvimento da rede Burger King e Loja Riachuelo com o mercado $\begin{array}{ll}\text { LGBTQI+ } & 20\end{array}$

4.3. Descrição do perfil dos entrevistados 23 
4.4. Descrição e análise dos resultados da primeira etapa de pesquisa 24

4.5. Descrição e análise dos resultados da segunda etapa de pesquisa 29

5 Conclusões e recomendações para novos estudos

5.1. Implicações gerenciais 33

5.2. Sugestões e recomendações para novos estudos 34

6 Referências Bibliográficas $\quad 35$

$\begin{array}{ll}\text { Anexo } 1 & 37\end{array}$

$\begin{array}{ll}\text { Anexo } 2 & 39\end{array}$

$\begin{array}{ll}\text { Anexo } 3 & 40\end{array}$

$\begin{array}{ll}\text { Anexo } 4 & 41\end{array}$ 


\section{Lista de figuras}

Figura 1: Comparativo por faixa de renda entre casais heterossexuais e

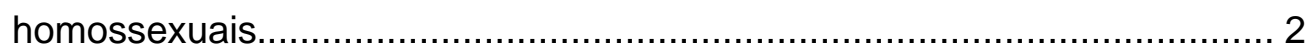

Figura 2: Peça da campanha publicitária realizada pela GAP em 2016, intitulada de "Love comes in every shade" ....................................................... 11

Figura 3: Pesquisa de mercado sobre marketing de causa, realizada pela consultoria Cause, em 2019............................................................ 14

Figura 4: Ação de marketing realizada pelo Burguer King para Parada do Orgulho de São Francisco, Estados Unidos, em 2014...................................... 21

Figura 5: Página oficial da Riachuelo dedicada a coleção pride 2019 .............. 23

Figura 6: Trajeto destacado com as cores da bandeira ..................................... 25

Figura 7: Página oficial da Uber destinada a comunidade LGBTQI+ ............... 26

\section{Lista de Tabela}

Tabela 1: Perfil dos entrevistados na primeira etapa 23

Tabela 2: Perfil dos entrevistados na segunda etapa 24 


\section{Introdução}

As empresas utilizam ações de marketing para o lançamento de novos produtos ou serviços no mercado, dessa forma, a empresa busca se tornar presente na memória do consumidor e conquistar o market share. Uma peça publicitária possui como objetivo divulgar um determinado produto ou serviço, informando aos clientes seus atributos e benefícios. A elaboração desse conteúdo muita das vezes é moldada para um determinando perfil de cliente, denominado público-alvo pretendido. Churchill e Peter (2012, p. 209) destacam que "servir apenas uma parte do mercado total é muitas vezes a estratégia mais eficiente, especialmente quando essa parte do mercado responde por uma porcentagem considerável das vendas de um produto".

O número de empresas que desenvolveram conteúdos publicitários de caráter social, aumentou nos últimos anos, se tornando recorrente a abordagem de temas que discutem racismo, sexismo e homofobia. A preocupação em torno dessas pautas, está relacionada às exigências da sociedade moderna, sendo mais propícia ao desenvolvimento de um diálogo e consciente sobre os problemas que envolvem o ambiente social. Vale ressaltar que durante muitos anos na cultura brasileira se predominou ideologias excludentes, baseadas em imposições religiosas ou estigmatizações, sendo um fator limitante para execução de algumas ações publicitárias em âmbito nacional.

As empresas possuem relevante papel para práticas sociais e ambientais, denominadas marketing de causa, sendo a designação atribuída para campanhas que buscam desenvolver produtos e ações organizacionais com um tema de causa social.

O censo realizado pelo IBGE em 2010 contabilizou 18 milhões de pessoas que se declaram membros da comunidade Lésbicas, Gays, Bissexuais, Transexuais/Transgêneros, Queer e Intersex (LGBTQI+), no Brasil, correspondendo a $9,0 \%$ da população total.

Um outro dado apresentado, compara a faixa salarial entre casais homossexuais versus casais heterossexuais no Brasil. Nesse levantamento, o 
primeiro grupo de casais apresenta maior representatividade nas faixas salarias mais altas, em relação ao segundo, conforme indicado no quadro abaixo:

Figura 1: Comparativo por faixa de renda entre casais heterossexuais e homossexuais.

\begin{tabular}{|l|l|l|}
\hline $\begin{array}{l}\text { FAIXAS DE } \\
\text { RENDA }^{\star}\end{array}$ & $\begin{array}{l}\text { CASAIS } \\
\text { HETEROSSEXUAIS }\end{array}$ & $\begin{array}{l}\text { CASAIS } \\
\text { HOMOSSEXUAIS }\end{array}$ \\
\hline $\begin{array}{l}\text { Até } 1 / 2 \\
\text { salário }\end{array}$ & $9,2 \%$ & $3,4 \%$ \\
\hline $\begin{array}{l}\text { Mais de } 1 / 2 \\
\text { a } 1 \text { salário }\end{array}$ & $18,72 \%$ & $15,6 \%$ \\
\hline $\begin{array}{l}\text { Mais de 1 a } \\
\text { 2 salários }\end{array}$ & $10,56 \%$ & $25,14 \%$ \\
\hline $\begin{array}{l}\text { Mais de 2 a } \\
\text { 5 salários }\end{array}$ & $10,56 \%$ & $20,5 \%$ \\
\hline $\begin{array}{l}\text { Mais de } 5 \text { a } \\
\text { 10 salários }\end{array}$ & $3,41 \%$ & $9,55 \%$ \\
\hline $\begin{array}{l}\text { Mais de 10 a } \\
\text { 20 salários }\end{array}$ & $1,05 \%$ & $3,77 \%$ \\
\hline $\begin{array}{l}\text { Mais de 20 } \\
\text { salários }\end{array}$ & $0,34 \%$ & $1,4 \%$ \\
\hline
\end{tabular}

Fonte: Censo IBGE (2010).

Em notícia no O Globo (2015), o público LGBTQI+, no Brasil, durante o ano de 2015 , possuía um poder de consumo, avaliado em torno de $R \$ 418,9$ bilhões, aproximadamente $10 \%$ do PIB daquele ano. Um outro dado importante é a movimentação gerada por esse público no setor de turismo, que de acordo com a Associação Brasileira de Turismo para Gays, Lésbicas e Simpatizantes (ABRATGLS), esse mercado teve um movimento estimado de $R \$ 150$ bilhões por ano, com expectativa de $\mathrm{R} \$ 300$ bilhões até dez anos na próxima década. Em comparação, o mercado americano movimenta aproximadamente US\$ 835 bilhões por ano, cerca de R $\$ 3.335$ bilhões por ano ${ }^{1}$ (SCRIVANO; NETO, 2015)

A Parada do Orgulho LGBT de São Paulo é considerada a maior do mundo, segundo Guinness World Records (2018). No ano de 2019 o evento recebeu apoio de diversas marcas, sendo os principais patrocinadores Burguer King, Avon, Amstel e Uber. Além disso, atraiu 3 milhões de pessoas,

\footnotetext{
${ }^{1}$ Cotação do dólar comercial a $R \$ 3,99$ no dia 14/05/2019.
} 
movimentando $\mathrm{R} \$ 403$ milhões, valor $40 \%$ maior em relação ao ano anterior, segundo o portal G1 - SP (PINHONI, 2019).

A abordagem de pautas mais sensíveis, como homossexualidade e racismo, promove debates na sociedade, sendo necessário a intervenção de agentes públicos.

No Brasil, o Conselho Nacional de Auto-regulamentação Publicitária (CONAR) é responsável por fiscalizar propagandas veiculadas nos meios de comunicação. Um caso de propaganda que trabalhou as relações homoafetivas e foi alvo de uma ação no CONAR, foi a realizada pelo O Boticário, em 2015, intitulada "Um dia dos namorados para todas as formas de amor", criada pela agência AlmapBBDO e dirigido por Heitor Dhalia, da Paranoid. Segundo o portal G1 (2015), a peça publicitária tinha como enredo principal o encontro romântico de casais de diferentes orientações sexuais trocando presentes. Essa ação da marca foi apresentada em território nacional, em emissoras de televisão. A propaganda recebeu duras críticas por parte do público, sendo acusada de "desrespeitosa à sociedade e à família", sendo então alvo de um processo no CONAR, a empresa posteriormente sendo absolvida do caso. Meses depois, a campanha recebeu o prêmio máximo na Effie Wards Brasil 2015 como melhor propaganda brasileira, G1 (2015).

\subsection{Objetivo principal}

O presente trabalho faz menção ao ambiente Lésbicas, Gays, Bissexuais, Transexuais/Transgêneros, Queer e Intersex (LGBTQI+). O desenvolvimento desse estudo tem como objetivo principal entender a percepção dos consumidores membros da comunidade sobre ações de marcas direcionadas ao público LGBTQI+.

Essa abordagem está relacionada ao aumento expressivo de empresas que se mostram solidárias ao movimento ou realizam uma ação de marca direcionada a esse público. No Anexo um contém alguns exemplos de ações desenvolvidas com a temática LGBTQI+ nos anos de 2018 e 2019.

\subsection{Delimitação do estudo}

O estudo aborda a atitude e percepção do consumidor diante do posicionamento adotado pelas empresas que apoiam a causa LGBTQI+. Tal ângulo de análise se mostra interessante devido à ligação que essas empresas 
possuem com a comunidade LGBTQI+. Além disso, existe um debate em torno das organizações que se utilizam desse público, visando apenas o retorno financeiro e não levando em consideração a causa em si.

Desse modo, pode surgir a possibilidade de um efeito reverso com essas ações publicitárias, proporcionando o afastamento do consumidor e a desconfiança em relação a marca.

Embora relevante, não se pretende tratar dos motivos que levam as organizações a adotarem ações de marketing com temática LGBTQI+ e o retorno obtido.

\subsection{Relevância do estudo}

As informações geradas nesse estudo podem colaborar para as ações futuras de marketing direcionadas à comunidade LGBTQI+. Um outro impacto é com relação a forma em que empresas podem se posicionar para atingir esse nicho do mercado. 


\section{Referencial teórico}

Neste capítulo são apresentados e discutidos aspectos conceituais e estudos relacionados ao tema que servem de base para a análise.

Esta seção está dividida em três partes, respectivamente, o comportamento do consumidor, o posicionamento de marca e a relação cliente e marca. Desse modo, contextualizando o problema de estudo sobre a percepção e atitude do consumidor entorno dos posicionamentos de marca com cunho LGBTQI+.

A primeira seção discute o comportamento do consumidor e suas implicações para tomada de decisão dos clientes. Além disso, é abordado a atitude do consumidor e sua implicação gerencial. Para desenvolvimento desses assuntos foi utilizado o autor Solomon (2016).

Na segunda seção discutem-se as perspectivas de Churchill e Peter (2012) e Kotler e Keller (2012) sobre o posicionamento de marca.

Por fim, a última seção aborda o relacionamento das marcas frente ao novo perfil do consumidor do século XXI, que diante do advento das novas tecnologias, adotou uma postura mais exigente Kotler e Keller (2017).

\subsection{Comportamento do Consumidor}

O comportamento do consumidor, de acordo com Solomon (2009, p.33) "é o estudo dos processos envolvidos quando indivíduos ou grupos selecionam, compram, usam ou descartam produtos, serviços, ideias ou experiências para satisfazerem necessidades e desejos". Desse modo, esse campo busca entender o comportamento das pessoas durante todo processo de aquisição de um produto ou serviço, investigando fatores que estão atrelados ao antes, durante e pós compra.

As organizações ao desenvolverem ações de marketing, buscam criar no consumidor o desejo de adquirir algo, de modo a estabelecer uma conexão com o seu público-alvo. "Muitas vezes as pessoas compram produtos não pelo que eles fazem, mas pelo que eles significam" (SOLOMON 2016, p. 16). Além disso, os consumidores têm personalidades diferentes, com traços e gostos em constantes modificações, conforme o meio social se desenvolve e novos padrões vão surgindo. "Nossa sociedade está evoluindo de uma cultura de massa, em que 
muitos consumidores têm as mesmas preferências, para uma cultura diversa, em que temos uma quantidade quase infinita de opções" (SOLOMON, 2016, p. 9).

De acordo com Churchill \& Peter (2012, p. 157), o processo de compra do consumidor recebe influências sociais, sendo estas relacionadas aos grupos que constituem a sociedade, tendo como principais fatores a cultura, subcultura, classe social, grupos de referência e família.

Ao colocar o consumidor no centro das ações de marketing, as organizações estão buscando um envolvimento com seu cliente. Contudo, essa ligação tem uma duração de tempo limitada, visto que os clientes possuem outras ocupações que demandam mais do que a preocupação com as marcas que consomem, segundo Kotler e Keller (2006), as empresas devem buscar compreender a melhor forma de atingir o seu público-alvo, visto a tamanha diversidade do mercado. Desse modo, o baixo grau de envolvimento do consumidor, pode ser compreendido diante da diversidade e o baixo envolvimento na tomada de decisão para alguns segmentos de produtos.

\subsubsection{Percepção do consumidor}

A percepção é um processo de tradução da sensação, sendo essa relacionada com os receptores sensórias do corpo humano. A emissão de estímulos pelas organizações é conhecida como marketing sensorial. De acordo com Solomon (2009, p.83), o impacto das sensações visa melhorar a experiencia do cliente durante o processo de compra.

As organizações buscam desenvolver ações de marketing de modo a atingir a percepção do consumidor. Segundo Solomon (2009, p.83), a "percepção é um processo de três estágios que traduz estímulos em significados". Essas etapas são: exposição, ocorrendo quando um estímulo é introduzido em um indivíduo. A segunda fase é a atenção, estando essa relacionada ao grau em que o estímulo reflete na pessoa. E por último a interpretação, sendo essa relacionada ao significado que a pessoa concede ao estímulo recebido. Além disso, a percepção sofre influências do ambiente cultural de cada consumidor, sendo esse um fator que interfere na interpretação do que está sendo oferecido.

As organizações para alcançarem o público LGBTQI+ utilizam estímulos visuais, através da aplicação das cores da bandeira LGBTQI+ em seus produtos e campanhas, uma outra forma é o uso de bordões comuns a esse grupo. Um estímulo auditivo é relacionado ao gênero musical POP, em especial grandes hits das maiores cantoras POP dos últimos anos. Esse ritmo musical é bastante 
comum entre a maioria dos membros da comunidade LGBTQI+, desse modo, muitas marcas utilizam essa tática e em alguns casos contratam os artistas para participarem de ações de marketing que visam alcançar esse nicho.

\subsubsection{Cultura}

A cultura é um espelho da sociedade, através dela é possível compreender determinados comportamentos, valores e crenças, sendo um reflexo do meio social, conforme Solomon (2016, p. 79) define, "é a acumulação de significados, rituais, normas e tradições compartilhados entre os membros de uma organização ou sociedade". Desse modo, o contexto cultura em que cada indivíduo está inserido, reflete na personalidade do consumidor.

A cultura desenvolve um papel fundamental no consumo dos indivíduos, sendo uma forma de determinar comportamentos, hábitos, estilos e crenças. Por exemplo, uma organização que busca ingressar em um novo mercado, tem que compreender a cultura local, tendo em vista que ela possibilita identificar oportunidades e ameaças existentes nesse ambiente. Desse modo, é possível adequar o produto ou serviço ao meio em que ele será inserido, além de amenizar potenciais chances de fracasso.

O ambiente está em constante transformação, as novas mídias estão todo momento trazendo novas ideias e conceitos, buscando alcançar determinados grupos. As pessoas realizam um processo de seleção cultural, a partir de um conjunto de símbolos que são expostas a elas através dos canais de comunicação, a observação individual também se aplica na tomada de decisão, da mesma forma que a opinião de outras pessoas realiza a mesma interferência.

Os indivíduos estão inseridos em um ambiente que possui características próprias, sendo um reflexo de conjuntos de hábitos e valores. A cultura é o perfil dessa sociedade e reflete a persona desses indivíduos de uma forma geral, além disso, sofrem influências de agentes externos que buscam inserir novos estilos e comportamentos a um determinado público, através do processo de produção de cultura. Solomon (2016, p. 89) define o sistema de cultura como "um conjunto de indivíduos e organizações responsáveis pela criação e comercialização de um produto cultural". 


\subsubsection{Subcultura}

A partir da compreensão do conceito de cultura, sendo ele um conjunto de valores e comportamentos que refletem uma sociedade, onde as pessoas buscam se adequar aos padrões esperados de sua cultura, poderemos entender 0 conceito de subcultura, sendo fruto de uma cultura existente. De acordo com Solomon (2009, p. 516), subcultura é "um grupo cujos membros têm crenças e experiências em comum significativas que os distinguem de outras pessoas". Em complemento, Kotler e Keller (2017, p.164), destaca que o poder não reside nos indivíduos, mas nos grupos sociais aos quais eles pertencem.

A subcultura é composta de diversos grupos, que compartilham entre si valores, características e hábitos próprios, estando atrelados ao gênero, religião, etnicidade e lugar. Esses elos buscam definir a essência de cada indivíduo dentro da sociedade. "Identidade social é a parte do eu definida pelos grupos aos quais estamos afiliados" (SOLOMON, 2016, p. 405). O atual cenário constitui uma sociedade voltada para o consumo, com a criação de uma identidade do consumidor associada a produtos ou serviços.

Ao buscar entender os diversos grupos que compõem uma subcultura, a identidade de gênero é um dos pontos mais importante para se compreender, pois está associado aos papeis sexuais que cada gênero exerce dentro de uma sociedade. De acordo Solomon (2016, p. 205-206), esses papeis refletem o modo como os indivíduos de determinado gênero devem agir, vestir-se ou falar. $O$ gênero biológico, sendo ele masculino e feminino, não está necessariamente atrelado ao fato de como as pessoas irão se comportar, ou seja, elas podem não exibir características, que foram de modo estereotipado, determinado a um gênero em específico. Segundo Eileen Fischer e Stephen J. Arnold (1994, p. 82-163), "os sentimentos do consumidor a respeito de sua sexualidade também são cruciais". Além disso, os hábitos e comportamentos podem se diferenciar entre culturas, desse modo, uma atitude considerada normal em um ambiente, pode não ser considerada em outra.

Relacionado a identidade de gênero, o segmento LGBTQI+ vem ganhando espaço nos últimos anos, e se destacado com uma forte subcultura. Segundo NUNAN (2013, p.148), o grupo LGBTQI+ surge como forma de resistência à ideologia dominante, representada através de comportamentos ou uso de objetos materiais. Para McCraken (2003), grupos que são excluídos pela identidade social dominante, como os homossexuais, são "provedores de significado" e pioneiros de tendências. É importante ressaltar que nos últimos anos o número de pessoas 
que se declararam pertencentes a esse grupo, vem aumentando, no censo realizado pelo IBGE em 2010, identificou na população brasileira cerca de 18 milhões de pessoas, atualmente estima-se que esse número ultrapasse 20 milhões de pessoas, alcançando a marca de $10 \%$ da população brasileira.

A transformação no cenário atual está atrelada a uma maior abertura da sociedade para o diálogo sobre diversidade de gênero, e resultado de iniciativas públicas, que buscam a redução e criminalização da homofobia. Essas práticas estão relacionadas com a ideia de cidades inclusivas, que buscam reduzir as diferenças entre as pessoas, concederem oportunidades e criar um ambiente de acolhimento e aceitação.

\subsubsection{Atitude do consumidor}

A percepção do consumidor é um processo de tradução sensorial dos estímulos emitidos por uma organização. Em contrapartida, a atitude do consumidor, de acordo com Solomon (2016), está relacionada a reação que um individuo possui diante de algo que está sendo exposto a ele, podendo ser uma resposta favorável ou não. Para alcançar o cliente LGBTQI+, as empresas buscam desenvolver ações que utilizam símbolos e elementos dessa subcultura, de modo a despertar a percepção desses consumidores. Logo, a atitude está relacionada a interpretação que essas pessoas realizam a partir dos estímulos recebidos.

Segundo Solomon (2016), a atitude gerada por um indivíduo pode ser uma coerência cognitiva, sendo essa relacionada a uma uniformidade no comportamento e posicionamento realizado. Em relação a comunidade LGBTQI+, uma empresa que adota um posicionamento pró-causa, espera-se que ela desenvolva ações que ajude o movimento. Além disso, é necessário que a organização tenha iniciativas internas e externas coerente com essa subcultura, através de um discurso que englobe a diversidade. Contudo, uma empresa que adota um posicionamento pró-LGBTQI+, porém não tem inciativas nem um discurso coerente com a comunidade, está promovendo uma dissonância cognitiva, ou seja, adota uma postura que está divergência, promovendo um conflito.

A atitude dos consumidores está relacionada com o conteúdo da mensagem que está sendo emitido para ele. Desse modo, as empresas buscam criar um grau de envolvimento com seu cliente, de modo a influenciar no comportamento do consumidor. 


\subsubsection{Influência no processo de compra}

A influência no processo de compra, além se sofrer interferências da cultura, subcultura e classe social, também é influenciada pelo composto de marketing, sendo formado pelo produto, preço, canal de distribuição e comunicação de marketing. Por fim, um último fator que atua na tomada de decisão dos consumidores, são os fatores situacionais, que englobam o ambiente físico, ambiente social, tempo, tarefa e condições momentâneas. De acordo com Kotler e Keller (2006, p.186), os clientes destacam diante dos estímulos recebidos, respostas em seu consciente, sobre o ambiente em que está inserido e para as ações de marketings que estão sendo direcionadas a ele.

O envolvimento com o cliente é fundamental para o processo de tomada de decisão, sendo uma forma de a empresa obter a atenção do consumidor e conseguir com que ele tenha uma boa impressão em torno do produto oferecido. Segundo Solomon (2016, p.163-171), as empresas podem desenvolver três tipos de envolvimento com os seus clientes:

1) Envolvimento com o produto - Está relacionado ao nível de interesse do consumidor por um produto, de modo que quanto mais as empresas conseguirem vincular uma marca a um indivíduo, maior envolvimento ela irá obter.

2) Envolvimento com a mensagem - Os veículos de comunicação utilizam formas criativas de repassar o conteúdo principal, de modo a capitar a atenção do consumidor na mensagem exibida.

3) Envolvimento Situacional - Personalização da mensagem para o consumidor, buscando captar a atenção do cliente no ato da compra.

As organizações ao desenvolverem conteúdos publicitários direcionados ao segmento LGBTQI+, estão buscando criar um maior envolvimento da marca com esse público em específico, de modo a atrair a atenção desses consumidores em potencial utilizando características pertencentes a esse grupo. Além disso, elas estão adotando um posicionamento diante da sociedade.

\subsection{Posicionamento de marca}

O posicionamento de marca é fundamental para que as organizações possam se diferenciar no mercado e conquistar o seu mercado-alvo. Ries e Trout (2000), destacam o posicionamento como "a ação de projetar a oferta e a imagem da empresa para que ela ocupe um lugar diferenciado na mente dos consumidores a fim de maximizar a vantagem potencial da empresa" 
As empresas adotam estratégias de posicionamento, para afirmar uma visão que os clientes potenciais terão a respeito do produto. De acordo Solomon e Elnora W. Stuart (2016), existem 8 dimensões para estabelecer uma marca no mercado, sendo elas: Estilo de vida, Liderança de preço, Atributos, Classe de produto, Concorrentes, Ocasiões, Usuários e Qualidade. Por exemplo, uma empresa que tem como público-alvo o segmento LGBTQI+, está assumindo um posicionamento por usuário. Desse modo, as organizações traçam o perfil desse usuário, buscam criar uma estratégia de comunicação ou desenvolver um produto ou serviço, que esteja alinhada com esse consumidor potencial. É importante ressaltar que a comunicação é fundamental para que se atinja o mercado-alvo desejado.

Uma marca que adotou um posicionamento apoiando a causa LGBTQI+ foi a GAP, utilizando uma foto de um casal masculino em sua rede social para promoção da campanha "Love comes in every shade" no ano de 2006 , com a seguinte legenda: "Cada família é única e muitas vezes vai além dos nossos parentes. Ela também inclui as pessoas que compartilham nossas vidas e paixões mais profundas" (VEJA.com, 2015).

É importante ressaltar que existem marcas que adotam posicionamentos que não condizem com sua estratégia de atuação, provocando um desencontro entre as atitudes da organização e a imagem que ela quer passar para o mercado: Figura 2: Peça da campanha publicitária realizada pela GAP em 2016, intitulada de "Love comes in every shade".

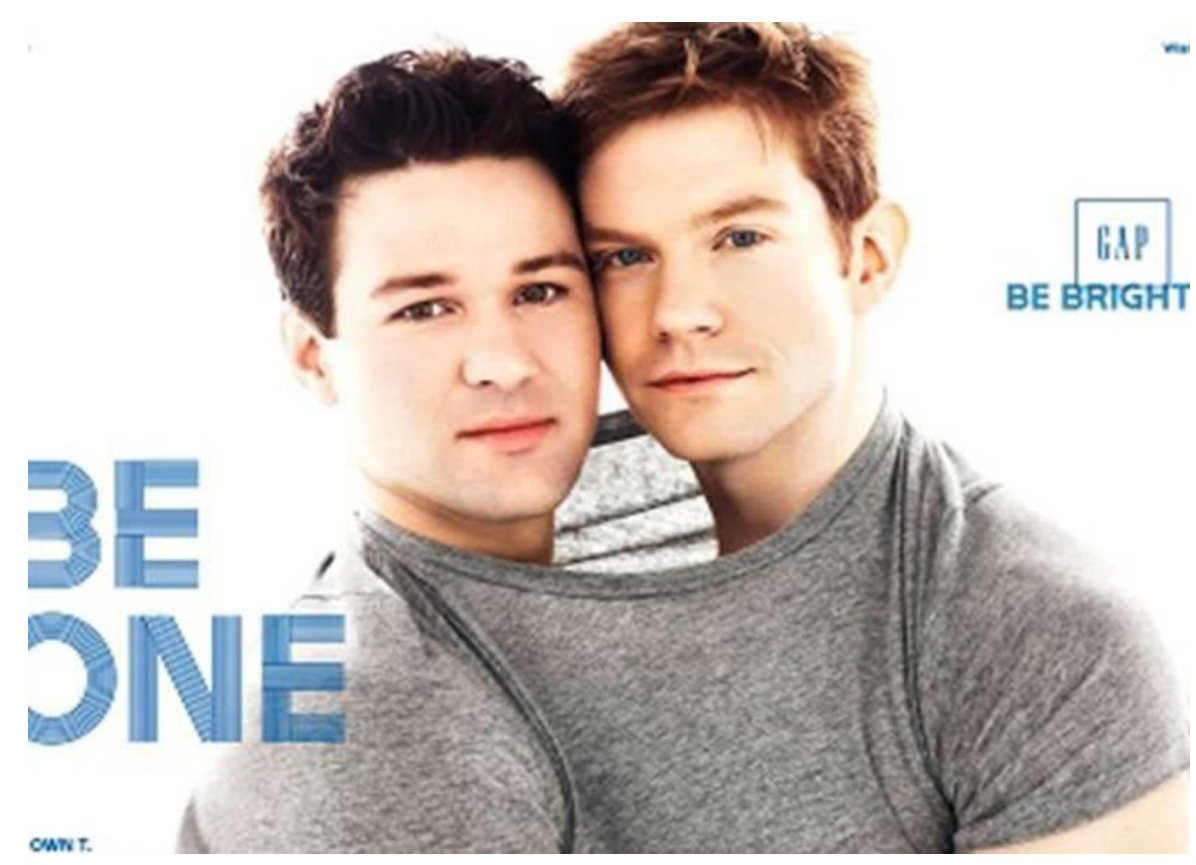

Fonte: VEJA.com (2015). 


\subsection{Relacionamento com os clientes}

Nos últimos anos os consumidores vêm apresentando um comportamento mais exigente, forçando as grandes empresas a adotarem um posicionamento diante dos problemas sociais e ambientais. Esse cenário ganhou força com o avanço tecnológico e o advento das redes sociais, que gerou um maior acesso à informação e abriu a possibilidade de as organizações realizarem um contato mais próximo de seu público-alvo.

O advento das novas tecnologias revolucionou os meios de comunicação, em especial a forma como as marcas se relaciona com os seus clientes. Além disso, os consumidores estão mais informados e empoderados, o que exige um maior cuidado das empresas. As trocas de informações entre as pessoas a respeito das marcas, possuem uma maior credibilidade no mercado, em relação as próprias ações de marketing. Desse modo, a tomada de decisão do consumidor vem sendo influenciada de forma forte pelos seus círculos sociais. Segundo Kotler e Keller (2017, p.21), "é como se estivessem se protegendo de alegações falsas das marcas ou de campanhas publicitarias ardilosas e usando seus círculos sociais para construir uma fortaleza".

Tradicionalmente os consumidores sofreram ao longo da história fortes influências das ações de marketing, através de propagandas focalizadas, que tratam o cliente como um alvo. Essas atitudes de origem vertical, ou seja, partem de uma esfera maior, nesse caso a empresa emissora, e buscam alcançar o cliente final. Além disso, outros influenciadores, sendo aqueles que possuem um maior conhecimento sobre o produto ou serviço, também servem de impulsionadores para a tomada de decisão do consumidor.

Contudo esse cenário sofreu grandes alterações nos últimos anos, as propagandas já não surtem tanto efeito no cliente, pois a opinião dos grupos sociais se mostra mais relevante no plano atual. É importante ressaltar que a construção desse meio está associada a expansão do acesso as redes sociais e plataformas de avaliação. Portanto, o relacionamento entre clientes e marcas está mais horizontal, tendo em vista que o cliente está em busca de consumir de empresas que compactuam com seus valores e princípios. "Os consumidores não são mais alvos passivos; estão se tornando mídias ativas de comunicação [...] É praticamente impossível esconder falhas ou isolar reclamações de clientes em um mundo transparentes e digital" (KOTLER, e KELLER, 2017, p. 28-29).

O segmento LGBTQI+ se mostrou muito promissor nos últimos anos e isso atraiu atenção de diversas marcas, que buscaram se apoiar na causa como forma 
de vender uma ideia de diversidade e igualdade para o mercado. Nos últimos anos o número de empresas que passaram a utilizar a bandeira do movimento em seus anúncios ou nos próprios produtos, reforça o potencial de consumo desse nicho. No entanto, na mesma proporção que organizações passaram a apoiar o movimento, o número de clientes atentos e cobrando posicionamento das marcas também aumentou, principalmente quando uma empresa apoia a causa, mas possui uma postura ou histórico, que está de desencontro com a causa. Os consumidores estão bastante atentos às atitudes das empresas, as redes sociais são canais de comunicação direta entre a empresa e o cliente final, em especial o Facebook e Twitter.

\subsubsection{Marketing de causa}

O termo marketing de causa é a designação que vem sendo atribuída para campanhas, desenvolvimento de produtos e ações organizacionais que buscam trazer uma mudança da percepção dos indivíduos sobre suas atitudes em comunidades e em relação ao meio ambiente. Uma pesquisa realizada pela consultoria Kantar com 20.000 consumidores, constatou que o valor de marca das organizações reconhecidas por adotarem um propósito cresceu $175 \%$ nos últimos 12 anos, desse modo, o marketing de causa tem se tornado uma tendência mundial (FILIPPE, 2019).

Uma segunda pesquisa acerca do conhecimento do consumidor brasileiro sobre marketing de causa, realizada pela consultoria Cause, em 2019, com 1200 brasileiros, relatou que $29 \%$ dos entrevistados tinham conhecimento do termo, dentro dessa amostra, cerca de 38\% representavam a geração Z (1995-2009) (FILIPPE, 2019). Desse modo, é possível compreender que as gerações mais novas estão atentas nas ações de marcas, principalmente aquelas relacionadas com causas sociais. Esse dado pode estar relacionado com a influência da internet que exerce nesse grupo social, onde o acesso a notícia se tornou mais dinâmico e de mais alcance. A imagem abaixo traz mais informações acerca do estudo realizado pela consultoria. 
Figura 3: Pesquisa de mercado sobre marketing de causa, realizada pela consultoria Cause, em 2019.

\section{CONSUMO COM CAUSA}

Um levantamento feito com 1200 brasileiros indica que parte dos consumidores reconhece e prefere empresas que criam iniciativas para beneficiar a sociedade

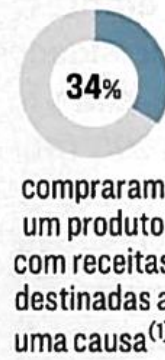

$33 \%$

\section{doaramo} troco de uma compra para uma causa no caixa da loja $^{(1)}$

\section{$23 \%$}

preferiram comprar um produto que ajudava uma causa $^{(1)}$

29\% dos consumidorés conhecem a expressão "marketing de causa". Dos que sabem:

84\% são totalmente favoráveis às empresas apoiadoras

49\% consideram eficiente para associar as empresas às suas causas

(1) Nos últimos 12 meses Fontes: Cause e Ipsos

Fonte: Exame (2019) 


\section{Métodos e procedimentos de coleta e de análise de dados do estudo}

Este capítulo pretende informar sobre as diversas decisões sobre a forma como este estudo foi realizado.

Está dividido em cinco seções que informam, respectivamente, sobre as etapas de coleta de dados do estudo realizado, sobre as fontes de informação selecionadas para coleta de informações neste estudo. Na sequência, informa-se sobre os processos e instrumentos de coleta de dados realizados em cada etapa, com respectivas justificativas, sobre as formas escolhidas para tratar e analisa os dados coletados e, por fim, sobre as possíveis repercussões que as decisões sobre como realizar o estudo impuseram aos resultados assim obtidos.

\subsection{Etapas de coleta de dados}

Este trabalho foi realizado com duas etapas de coleta de dados em campo, com dois grupos totalmente diferentes, tendo como objetivo entender a atitude e percepção dos consumidores com a adoção de posicionamento de marcas direcionados ao público LGBTQI+. Ambas etapas são de caráter qualitativo e foram realizadas em momentos diferentes, com um intervalo de tempo de três meses entre elas. $O$ estudo foi conduzido dessa forma com o intuito de explorar as ações de marcas realizadas durante o mês do orgulho LGBTQI+, que ocorrem anualmente no mês de junho. Desse modo, foi possível verificar quais impressões foram geradas no consumidor no "boom", onde diversas marcas fizeram alguma ação, como Chevrolet, Skol, Amstel Burguer King, Starbucks, Riachuelo, Renner e outras tantas. O período posterior foi possível identificar quais marcas permaneceram e continuaram sendo citadas pelos consumidores.

A primeira etapa consistiu na realização de entrevistas presenciais no dia da $23^{\circ}$ Parada do orgulho LGBTQI+ de São Paulo, no dia 23 de junho de 2019. A escolha do evento para realizar a primeira etapa tem relação com a quantidade de marcas que estavam associando a sua imagem com o movimento e o evento. Nesse período ocorreram diversas ações de marketing em mídias digitais e pontos físicos, em especial nos estabelecimentos próximos à Avenida Paulista, a grande maioria das ações tendo sofrido adaptações visuais por conta do evento. No meio 
virtual, diversas empresas realizaram algum tipo de publicação ou campanha publicitária direcionada ao público LGBTQI+. Além disso, algumas empresas lançaram edições limitadas para o mês do Orgulho LGBTQI+, sendo alguns produtos distribuídos somente em São Paulo, em função do evento.

A segunda etapa foi realizada com indivíduos que participaram da $23^{\circ}$ Parada do Orgulho LGBTQI+ de São Paulo. Nessa fase do estudo foram realizadas entrevistas pessoalmente ou via chamada de vídeo ou ligação de áudio, através das plataformas WhatsApp e Instagram. O objetivo foi identificar quais marcas continuavam sendo citadas ao questionar o relacionamento com o segmento LGBTQI+ e identificar se algumas das ações de marketing realizadas surtiram efeito no consumidor. O roteiro de entrevistas utilizado como base para realização das entrevistas na segunda etapa foi semelhante ao da primeira, desse modo, foi possível manter um padrão de respostas esperadas, entre as etapas. Ambos roteiros estão incluídos no anexo dois desse estudo.

Em ambas etapas os participantes do estudo foram informados que a entrevista estaria sendo gravada em formato de áudio, e todos concordaram com a realização dela.

\subsection{Fontes de informação selecionadas para coleta de dados no estudo}

A realização desse estudo teve como proposito identificar as atitudes e percepções dos consumidores sobre as marcas que possuem seu posicionamento direcionado ao segmento LGBTQI+, através de entrevistas realizadas presencialmente ou canais virtuais, obtendo um grupo de 30 respondentes. Ambas seguiram um roteiro semiestruturado, previamente elaborado com o intuito de traçar as impressões dos consumidores.

$\mathrm{Na}$ primeira etapa foram realizadas entrevistas pessoais com participantes da Parada do Orgulho LGBTQI+ em São Paulo, selecionadas de forma assistemática, duas horas antes do início do horário previsto para o evento. Nessa etapa do estudo foram entrevistadas 15 pessoas entre 20 e 35 anos, pertencentes ou simpatizantes com o movimento LGBTQI+.

$\mathrm{Na}$ segunda etapa foram entrevistadas um novo grupo de 15 pessoas que participaram do evento em São Paulo, apresentando idade entre 19 a 31 anos, pertencentes ou simpatizantes com o movimento LGBTQI+. A seleção desse público foi realizada através das redes sociais, onde foi realizada uma postagem em um grupo no Facebook direcionado ao público LGBTQI+. com pessoas que 
possuem o perfil semelhante ao da primeira etapa. Desse modo, alguns demonstraram interesse em participar da pesquisa.

Os perfis dos entrevistados são de consumidores conectados às redes sociais e membros ou simpatizantes da comunidade LGBTQI+. Importante ressaltar que muitas ações de marketing ocorreram no ambiente virtual. A escolha pelo número de entrevistados nas duas etapas se deu pela repetição das respostas, ou seja, a partir de então poderia ser esperada alguma repetição de respostas às já obtidas.

\subsection{Procedimentos e instrumentos de coleta de dados utilizados no estudo}

Esse estudo foi desenvolvido com base no método de pesquisa qualitativo, com o intuito de mapear a imagem que o consumidor carrega diante das ações de marketing direcionadas ao público LGBTQI+. De acordo com Kotler e Keller (2017, p.108), a utilização de perguntas em aberto, possibilita os respondentes expressarem melhor a sua opinião, oferecendo mais informações para o estudo. A aplicação dessa metodologia possibilitou entender a percepção que esse mercado carrega e identificar quais marcas estão presentes na memória desses consumidores. Em suma, o estudo foi realizado em cima de um roteiro semiestruturado, que serviu de apoio para as entrevistas. É importante destacar que não foram realizadas entrevistas em profundidade, devido às limitações do ambiente na primeira etapa.

O instrumento foi construído por meio de entrevistas pessoais e gravadas com auxílio de um smartphone. Foi utilizado um roteiro semiestruturado como base, cujo objetivo era captar a opinião do consumidor e identificar as marcas que estavam presentes na memória das pessoas ao relacionar marca e movimento LGBTQI+.

Este instrumento foi aplicado devido à necessidade de obter o máximo de informações possíveis, sem causa grandes transtornos aos entrevistados, desse modo a realização de entrevistas se demonstrou ser mais eficaz para esta situação. É importante ressaltar que por se estar em um evento de grande porte, as perguntas deveriam ser simples e fáceis de serem respondidas. Desse modo, o roteiro foi desenvolvido para ser realizado no tempo médio de 10 minutos. $A$ maior parte dos entrevistados demonstraram interesse em participar da pesquisa e por essa razão algumas entrevistas superaram o tempo médio previsto. 
$\mathrm{Na}$ segunda etapa, as entrevistas ocorreram utilizando um roteiro bem similar ao da primeira etapa. Nesse momento, o objetivo é captar as percepções que ficaram na mente do consumidor após um período de três meses do evento da Parada LGBTQI+. A segunda etapa foi realizada durante o mês de setembro de 2019, abordando pessoas que participaram na 23ํ Parada do Orgulho LGBTQI+ em São Paulo.

Tomou-se o cuidado de não citar nas perguntas de pesquisa o nome das marcas que realizaram ações de marketing pela ocasião, durante a parte inicial da entrevista. Desse modo, foi possível identificar quais marcas estavam mais fortemente registradas na memória do consumidor. Somente nas três perguntas finais que eram reveladas ao entrevistado quais marcas estavam patrocinando 0 evento da Parada do Orgulho LGBTQI+. Além disso, na primeira etapa as entrevistas foram realizadas em ruas paralelas ao evento, com caráter mais residencial, assim evitando qualquer exposição de marca que pudesse ser avistada pela pessoa entrevista e pudesse vir a interferir na análise.

\subsection{Formas de tratamento e análise dos dados coletados para o estudo}

O tratamento de dados em uma pesquisa qualitativa, ocorre de forma diferenciada, não seguindo uma norma de cálculos estatísticos, como acontece em outras modalidades de estudo. Na pesquisa qualitativa o grupo de respondentes obtidos, é analisado de acordo com estilo do pesquisador (GIL, 2010, p. 175).

Na primeira e segunda etapas as informações coletadas foram consolidadas de acordo com a pergunta realizada, e em seguida foi classificada conforme a relevância da resposta para cada pergunta. Respostas breves ou muito genéricas foram desconsideradas. Desse modo, foi possível traçar as marcas mais comentadas, comparar as respostas dadas pelos entrevistados, buscando encontrar um padrão e identificar a percepção que os consumidores carregam.

Os grupos foram em um primeiro momento analisadas cada uma de forma individual, depois se comparou as respostas obtidas entre as duas fases.

Este tratamento é importante para realizar análises que possam ser confrontadas frente à teoria e identificar a opinião dos consumidores, além de mostrar o quanto o mercado está atento a essas ações de marca. 


\subsection{Limitações do Estudo}

$\mathrm{Na}$ primeira etapa antevê-se que o local escolhido para realizar as entrevistas deveria ser afastado do evento principal, de modo a evitar que os entrevistados pudessem ser influenciados por ações de marketing realizadas no momento e o barulho do evento. Desse modo, foi escolhida uma rua paralela à Avenida Paulista, sendo de caráter mais residencial. Apesar disso, ainda assim algumas respostas podem ter sofrido influência das ações de marcas realizadas.

A escolha por realizar as entrevistas da primeira fase antes do início do evento, se deu pela possibilidade de as pessoas estarem mais dispostas a responder a pesquisa do que durante a parada, mesmo assim ocorreu casos de pessoas que responderam algumas perguntas de forma mais superficial, mas se trata de casos isolados. Em relação às entrevistas realizadas com pessoas que estavam em grupo, adotou-se uma medida, onde foi solicitado que ela se distanciasse um pouco de seu grupo, evitando que outros pudessem interferir na resposta.

Na segunda etapa os entrevistados foram selecionados via uma rede social. Nenhuma das pessoas entrevistadas foram informadas antecipadamente sobre as perguntas que seriam feitas e nem o objetivo final da pesquisa, buscando não influenciar as respostas ou direcionar. As pessoas que participaram da primeira etapa não fizeram parte desse segundo momento. As entrevistadas na segunda fase ocorreram via WhatsApp ou Instagram, utilizando os recursos de chamada e chamada de vídeo, deixando o entrevistado optar por qual achava mais confortável.

Os participantes não foram questionados sobre dados pessoais, e em relação a sua orientação sexual, apenas foi consultado se pertenciam ou simpatizavam com o movimento, de modo a evitar possível desconforto para 0 entrevistado. 


\section{Apresentação e análise dos resultados}

Este capítulo, organizado em cinco seções apresenta e discute os principais resultados alcançados com as entrevistas, desse modo se analisa e discute suas implicações e produz sugestões sobre o estudo previamente selecionado.

A primeira aborda de forma breve o termo Pink Money e suas implicações no mercado atual. A segunda apresenta e descreve as duas empresas que foram mais citadas entre os entrevistados, Burger King e Loja Riachuelo. A seguir tratase do perfil dos entrevistados nas duas fases que ocorreram para a construção desse estudo.

A quarta e última fase ocorrem a interpretação dos resultados obtidos com as coletas de dados, traçando tendências no mercado e comparativos com o referencial teórico.

\subsection{Pink Money}

O advento da internet possibilitou o acesso à informação em diversos níveis, na mesma proporção a forma de consumir na sociedade foi influenciada. $O$ mercado LGBTQI+ se beneficiou com a pulverização da informação, além de conseguir atingir um maior número de pessoas, assim, o perfil desses consumidores se tornou mais evidente para as organizações.

O termo Pink Money é utilizado para fazer referência ao consumo da comunidade LGBTQI+. A expressão se tornou popular nos últimos anos diante do aumento no número de empresas e artistas que passaram a apoiar o movimento e, consequentemente associando a sua imagem ao grupo.

\subsection{A Envolvimento da rede Burger King e Loja Riachuelo com o mercado LGBTQI+}

O estudo busca entender a atitude e percepção do consumidor em torno do posicionamento das marcas direcionadas ao público LGBTQI+, nessa seção do estudo, são abordadas as empresas Burguer King e a Loja Riachuelo, visto que ambas realizaram ações de marketing direcionadas a esse nicho do mercado e foram as mais citadas durante as entrevistas. 
A rede de fast food Burger King vem construindo ao longo dos seus 60 anos de existência o seu envolvimento com a comunidade LGBTQI+. A marca, que se encontra presente em diversos países, carrega como um de seus princípios o respeito a diversidade no seu sentido mais abrangente, e reforça a importância da inclusão, conforme divulgado em sua página oficial na internet, em uma área dedicada exclusivamente para abordagem do tema. A rede de fast-food possui em seu posicionamento uma preocupação com a comunidade local e o empoderamento da personalidade de cada um de seus clientes. Desse modo, o apoio ao movimento LGBTQI+ é uma das causas que a empresa busca se conectar.

Uma das ações de marketing mais famosa realizada pela Burger King, direcionada a comunidade LGBTQI+ ocorreu em 2014, quando a empresa lançou o Proud Whopper durante a Parada do Orgulho de São Francisco, Estados Unidos. O produto possuía uma embalagem especial decorada com as cores da bandeira LGBTQI+. O ápice da ação era quando o cliente desembalava o hamburguer e descobria que não possuía nada de especial no produto, e que se tratava do tradicional Whopper. Na embalagem interna o cliente recebia a seguinte mensagem "somos todos iguais por dentro" (PORTUGAL, 2014).

Figura 4: Ação de marketing realizada pelo Burguer King para Parada do Orgulho de São Francisco, Estados Unidos, em 2014.

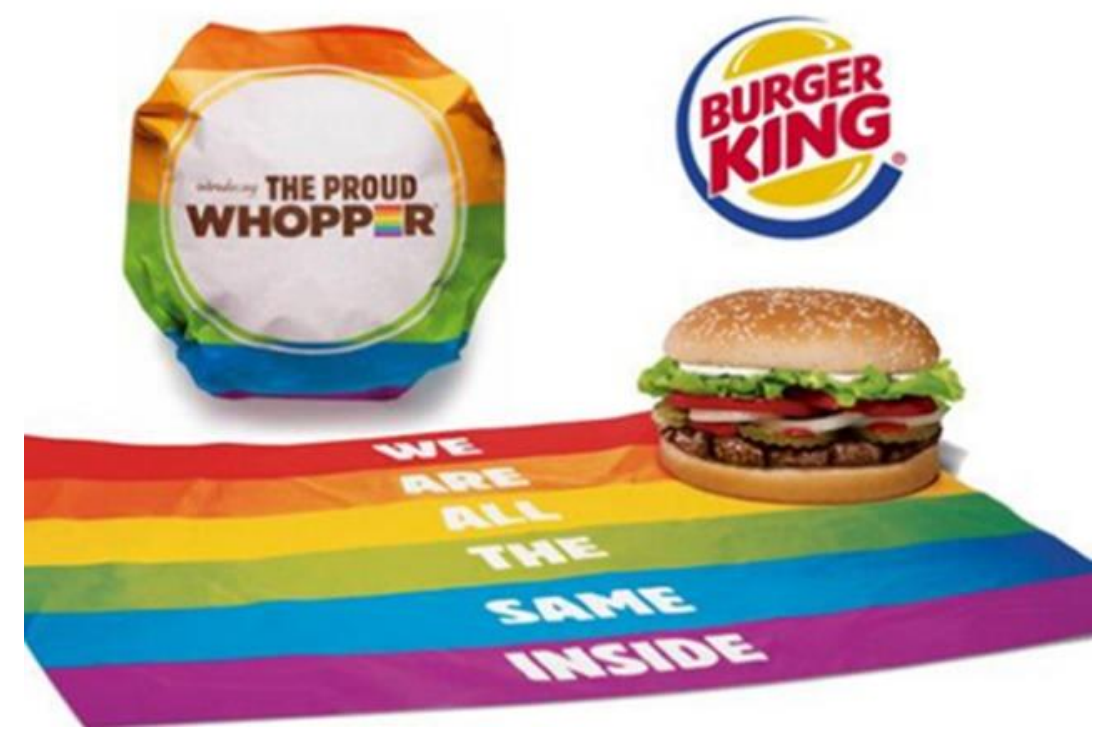

Fonte: Google Imagens (2014).

As ações de marketing direcionadas à comunidade LGBTQI+ desenvolvidas pelo Burger King Brasil começaram a se destacar em 2017, quando a empresa convidou a Drag Queen Anny B. para participar de um comercial, sendo 
essa a primeira vez que uma artista drag assumia um papel em uma campanha de marketing da empresa, e que foi distribuída em rede nacional (DEARO, 2017). No ano de 2018 e 2019, a empresa passou a patrocinar a Parada do Orgulho LGBTQI+ de São Paulo e desenvolver ações focadas no evento e no mês do orgulho LGBTQI+. No ano de 2019, em parceria com a Fini, empresa de doces e confeitos, foi lançado o milk-shake de arco-íris, cujo lucro com a venda do produto foi $100 \%$ destinada para a ONG Casa 1, que fornece assistência para comunidade LGBTQI+, em São Paulo (BELLONI, 2019). Logo, é perceptível o compromisso que a empresa tem com a causa, sendo um posicionamento constante, não possuindo um caráter momentâneo como é feito por outras organizações. No anexo três desse estudo encontram-se alguns exemplos de medidas tomadas pelo Burger King.

A loja Riachuelo, diferentemente da rede Burger King, não possui um histórico de apoio a comunidade LGBTQI+. No entanto, em entrevista concedida para o UOL (MOURA, 2019), a empresa se posiciona como a maior empregadora de transgêneros no Brasil, sendo cerca de 500 trabalhadores atuando na confecção dos produtos da marca, através da Guararapes Confecções, no Rio Grande do Norte. Além disso, a empresa comercializou em 2019 uma linha de produtos dedica à comunidade LGBTQI+. O anexo quatro contêm imagens da vitrine da loja Riachuelo na Oscar Freire, durante o mês do orgulho do LGBTQI+. A página dedicada à coleção ainda se encontrava disponível em sua página oficial em novembro de 2019.

A Riachuelo não possuía uma imagem forte em relação à comunidade LGBTQI+. Contudo, no ano passado, Flavio Rocha, atual presidente do conselho e ex-presidente da Riachuelo, apoiou o presidente Bolsonaro durante as eleições de 2018 e, se demonstrou contra ao casamento homoafetivo, em função de suas crenças religiosas. Tal posicionamento foi o suficiente para vincular a imagem da Riachuelo como uma das organizações que não apoiam a causa (MOURA, 2019). A situação se complicou com o lançamento da campanha Pride em 2019, onde a imagem da empresa diante da comunidade LGBTQI+ ficou negativa, visto que muitos interpretaram como uma forma de faturar em cima desse nicho. Essa perspectiva se refletiu durante as entrevistas realizadas para esse estudo, conforme apresentado mais adiante. 
Figura 5: Página oficial da Riachuelo dedicada a coleção pride 2019

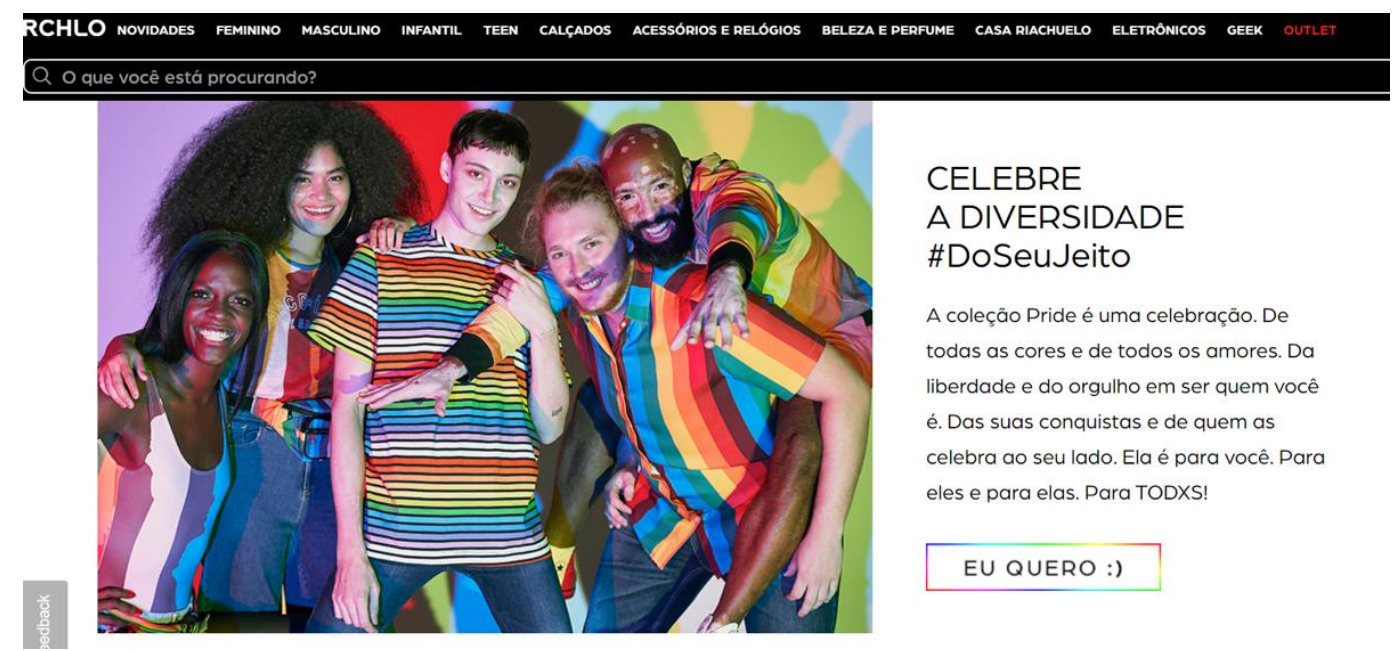

Fonte: Site Oficial da Riachuelo (2019)

\subsection{Descrição do perfil dos entrevistados}

A pesquisa foi realizada em dois momentos diferentes, sendo dois grupos de entrevistados totalmente diferentes, de modo a buscar compreender quais marcas se encontravam na memória do consumidor, assim como sua percepção sobre essas marcas que estão realizando ações direcionadas a comunidade LGBTQI+.

A primeira etapa ocorreu durante a Parada do Orgulho LGBTQI+ de São Paulo, no mês de junho de 2019. Nessa etapa foram selecionadas 15 pessoas.

Tabela 1: Perfil dos entrevistados na primeira etapa

\begin{tabular}{|ccll|}
\hline Nome & Idade & \multicolumn{1}{c|}{ Onde reside } & \multicolumn{1}{c|}{ Ocupação Profissional } \\
\hline E1 & 22 & São Paulo & Estudante de Engenharia \\
\hline E2 & 31 & Recife & Autônomo \\
\hline E3 & 22 & São Paulo & Estudante de Turismo \\
\hline E4 & 23 & São Paulo & Estudante de Pós em Fisologia \\
\hline E5 & 21 & São Paulo & Estudante de Marketing \\
\hline E6 & 27 & São Paulo & Psicologo \\
\hline E7 & 25 & São Paulo & Tradutor \\
\hline E8 & 31 & São Paulo & Funcionário Público \\
\hline E9 & 25 & São Paulo & Consultor de negocios \\
\hline E10 & 30 & Santos & Modelo \\
\hline E11 & 19 & São Paulo & Estudante de Marketing \\
\hline E12 & 23 & São Paulo & Estudante de Engenharia \\
\hline E13 & 24 & São Paulo & Estudante de Direito \\
\hline E14 & 27 & São Paulo & Autônomo \\
\hline E15 & 28 & São Paulo & Autônomo \\
\hline
\end{tabular}


Fonte: Elaboração própria (2019).

A segunda etapa ocorreu no mês de setembro e outubro de 2019, três meses depois do evento. Nessa fase foram selecionadas 15 pessoas que participaram da Parada do Orgulho LGBTQI+ através das redes sociais.

Tabela 2: Perfil dos entrevistados na segunda etapa

\begin{tabular}{|c|c|l|l|}
\hline Nome & Idade & \multicolumn{1}{|c|}{ Onde reside } & \multicolumn{1}{c|}{ Ocupação Profissional } \\
\hline F1 & 22 & Rio de Janeiro & Estudante de Relações Internacionais \\
\hline F2 & 29 & São Paulo & Analista de Risco \\
\hline F3 & 19 & São Paulo & Estudante de Engenharia \\
\hline F4 & 26 & Pará & Engenheiro Agronomo \\
\hline F5 & 20 & São Paulo & Estudante de Arquitetura e Urbanismo \\
\hline F6 & 21 & Rio de Janeiro & Estudante de Administração \\
\hline F7 & 23 & Rio de Janeiro & Produtor de Eventos \\
\hline F8 & 24 & Amazonas & Gestor de Franquia \\
\hline F9 & 24 & São Paulo & Estudante de Enfermagem \\
\hline F10 & 20 & São Paulo & Estudante de Empreendedorismo \\
\hline F11 & 25 & Santa Catarina & Vendedor \\
\hline F12 & 20 & Rio de Janeiro & Estudante de Direito \\
\hline F13 & 20 & São Paulo & Analista de Sistemas \\
\hline F14 & 22 & Santa Catarina & Estudante de Direito \\
\hline F15 & 26 & São Paulo & Engenheiro \\
\hline
\end{tabular}

Fonte: Elaboração própria (2019).

\subsection{Descrição e análise dos resultados da primeira etapa de pesquisa}

A primeira pergunta na entrevista buscava identificar quais ações de marketing com a temática LGBTQI+ que os consumidores se recordavam. Nessa primeira etapa do roteiro, muitos respondentes citaram as marcas Natura e $O$ Boticário, ambas do segmento de beleza. Outras duas marcas que foram citadas por praticamente todos os respondentes foi o Burger King e a Uber, ambas patrocinadoras da Parada do Orgulho LGBTQI+.

O Burger King, conforme descrito no tópico anterior, desenvolve diversas ações direcionadas para o grupo social durante o ano. Além disso, era segunda vez que a empresa estava como patrocinadora do evento. O entrevistado E4, lembrou a iniciativa de marketing da Burger King frente ao veto do comercial do Banco do Brasil, pelo presidente da república Jair Bolsonaro, onde a ação publicitaria trazia participantes de diversos gêneros e raça. Diante da censura, a rede de fast food convidou os participantes da propaganda da financeira a participar de um comercial em defesa da diversidade. 
Uma outra empresa citada pelos entrevistados foi a Uber, que possui iniciativas semelhantes à adotada pelo Burger King. Ao longo do ano, a empresa ao longo costuma enviar aos seus usuários e-mails institucionais que abordam diversos temas de inclusão social e respeito a diversidade. Uma outra iniciativa é a página oficial da Uber destinada a comunidade LGBTQI+, onde são apresentadas as iniciativas organizacionais para promover a diversidade no ambiente de trabalho, as prides ${ }^{2}$ em que a marca estará presente e um conteúdo explicando sobre cada gênero da comunidade LGBTQI+. Contudo, uma ação forte da empresa e que certamente influenciou as respostas dos consumidores está associada as mudanças realizadas no próprio aplicativo da empresa, onde a tradicional linha preta que indica o caminho do motorista até o usuário foi substituída pelas cores do arco-íris, símbolo da comunidade LGBTQI+. Além disso, essa funcionalidade foi aplicada nas principais Paradas do Orgulho realizadas em todo o país. É importante ressaltar que não é a primeira vez que a empresa realiza essa mudança, mas isso deve ter influenciado de uma certa forma na memória recente dos consumidores.

Figura 6: Trajeto destacado com as cores da bandeira

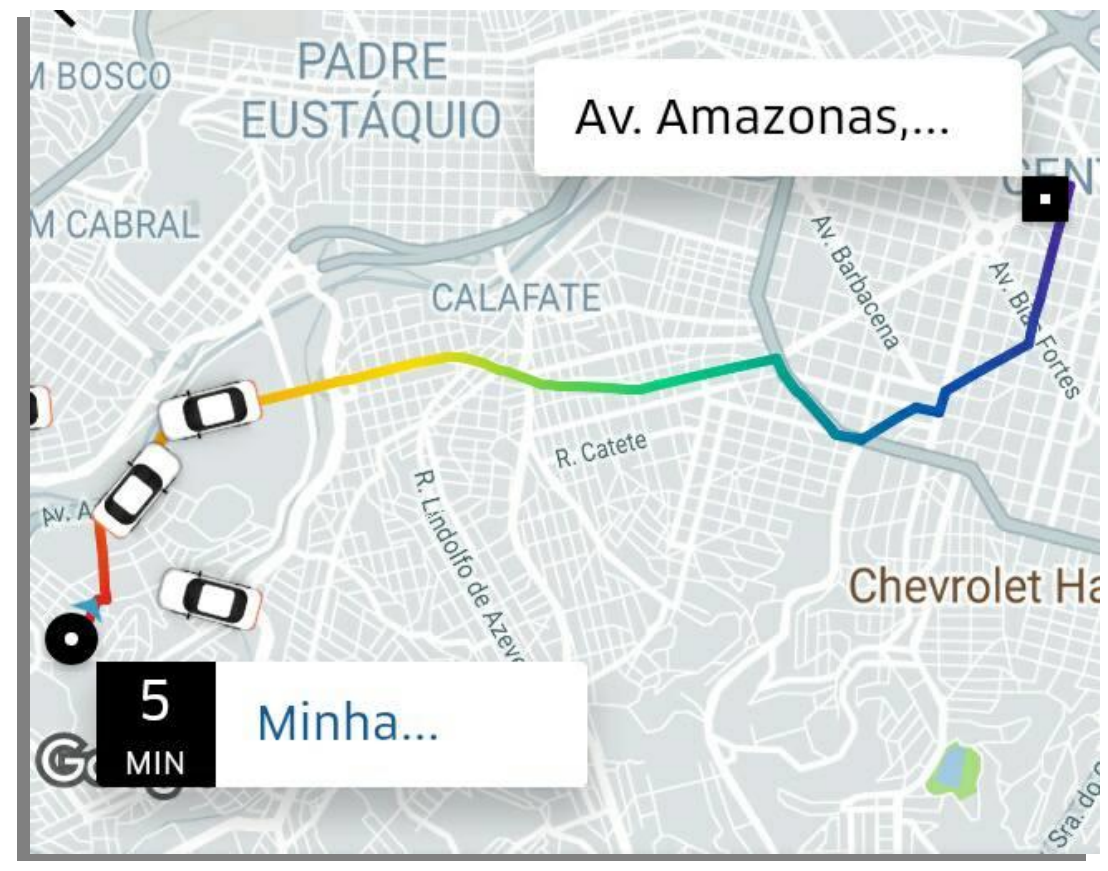

Fonte: Google Imagens (2019)

2 Pride - Termo em inglês que traduzido para o português significa orgulho. $\mathrm{Na}$ comunidade LGBTQI+ o termo é utilizado para fazer referência ao mês do Orgulho LGBTQI+ e aos eventos da comunidade, em especial as Paradas do Orgulho. 
Figura 7: Página oficial da Uber destinada a comunidade LGBTQI+

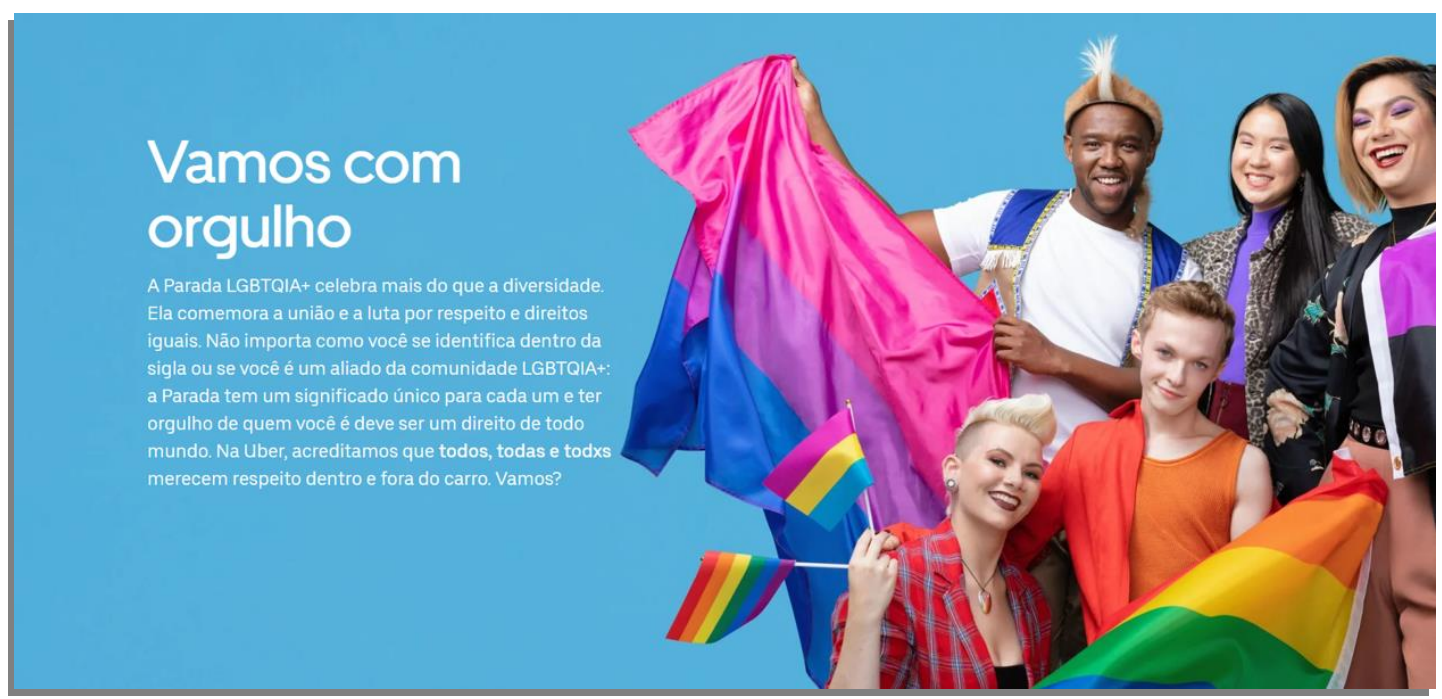

Fonte: Página oficial da Uber (2019)

A Avon esteve presente na Parada do Orgulho LGBTQI+ como patrocinadora oficial, mas não foi lembrada pelos entrevistados. Contudo, suas concorrentes foram mencionadas de modo espontâneo. Um fato a ser destacado, é a proximidade da data em que foi realizado o estudo com a comemoração do dia dos namorados, de modo a influenciar os entrevistados da $1^{\circ}$ fase, onde os respondentes E6, E9 e E11 citaram a Natura e Boticário por conta das ações na data comemorativa. O Boticário, executou uma ação de marketing para ocasião, onde se exaltava todas as formas de amor $(\mathrm{G} 1,2019)$. Além disso, a gerente de marca e mídia do Boticário em entrevista para Exame (FILIPPE, 2019), reforçou as diretrizes da empresa na preocupação desenvolver a diversidade, buscando ir além do ambiente externo da organização e passando adotar como objetivo no ambiente de trabalho. Uma outra empresa citada nas entrevistas foi a Natura, que por sua vez, é conhecida por realizar diversas ações de cunho social, possuindo uma imagem forte nesse aspecto.

Ao adotar um posicionamento por usuário, uma marca busca identificar quais traços são daquele segmento e aplicar isso a seus produtos. No caso da comunidade LGBTQI+, existe uma presença muito forte de valores e empoderamento da causa, assim as empresas buscam transmitir isso em suas coleções, estabelecendo um diálogo direto com esse público, valorizando o movimento. Essa atitude está associada ao novo cenário conforme descrito por Kotler e Keller (2017), onde o consumidor está atuando de forma direta com as organizações, é um relacionamento horizontal e mais próximo do usuário final. Além disso, nessa primeira pergunta podemos identificar os resultados das ações promovidas pelas organizações direcionadas à comunidade, onde alguns 
entrevistados citaram empresas que não estavam presentes no evento, mas realizam marketing de causa e desse modo foram associadas.

A segunda pergunta feita aos entrevistados tinha como objetivo entender se eles achavam importante que marcas apoiassem a comunidade LGBTQI+. Os respondentes destacaram a visibilidade e a força que o movimento ganha quando empresas adotam esse posicionamento, principalmente pelo fato do Brasil ser um país com histórico de homofobia. Além disso, os entrevistados destacaram a representatividade como um dos pontos fortes, "me sinto mais livre para me assumir no mercado de trabalho" - entrevistado E7. Desse modo, uma marca ao adotar esse tipo de posicionamento, tem a pretensão de estabelecer uma ligação com esse público, de modo a valorizá-los e transmitir confiança. O entrevistado E13, destaca a percepção negativa que a Riachuelo trás, "você sabe que o posicionamento é totalmente comercial, então necessariamente você não muda sua opinião em relação a eles". Ele também destacou a percepção quando às organizações apoiam a causa com o intuito de ajudar, "outras empresas você ver que estão atuando várias vezes, isso acaba surtindo um efeito mais positivo, porque você realmente se sente representado por essas marcas e vê que não tem nada de errado em ser quem você realmente é".

Esse sentimento que os respondentes trouxeram está associado ao ambiente cultural brasileiro, sendo um país que durante muito tempo predominouse ideais excludentes e que diminuíam a comunidade LGBTQI+. Atualmente esse público ganhou espaço e voz dentro da sociedade, e quando empresas demonstram seu respeito pela causa, desperta no público um sentimento de acolhimento e pertencimento.

A terceira pergunta está relacionada à interpretação que os consumidores possuíam sobre as marcas que apoiam o movimento. Desse modo, buscou-se entender se os entrevistados estavam observando essas ações como um ato de interesse próprio ou se realmente identificavam um interesse na causa. Os respondentes foram enfáticos em declarar que encaravam algumas empresas como clara apropriação para interesses próprios, sem que houvesse realmente uma preocupação com a causa. Segundo a maioria dos respondentes, isso ocorre por estar na moda vestir a bandeira da comunidade - "não fazem nada o ano inteiro e chega no momento da parada saem estampando o arco-íris nas roupas, e a venda desses produtos não revertido para uma causa" - entrevistado E4.

A comunidade LGBTQI+ possui características e valores próprios, com os quais os membros dessa subcultura se identificam. Logo se tornou comum ver lojas comercializando produtos com as cores da bandeira LGBTQI+, utilizando o 
símbolo da comunidade, expondo gírias e bordões que são comuns no meio. Todo esse comércio tem o intuito de se aproximar do cliente alvo. Contudo, o consumidor não tem observado essas medidas necessariamente como algo positivo - e os entrevistados reforçaram esse ponto de vista, destacando que o engajamento com a causa vai muito além da venda, que por sinal tem sido encarada como um aproveitamento em cima da causa.

Embora muitas pessoas tenham reforçado o caráter negativo, os entrevistados também sinalizaram para a existência de organizações que estão engajadas com o movimento, reforçando a importância dessas ações - "as crianças que estão crescendo com essas ações elas irão ter uma visão mais aberta sobre a causa" entrevistado E6. O público vê com bons olhos as organizações que realmente trazem algum proposito para a causa, através de um envolvimento social e geração de benefícios.

A pergunta seguinte tinha por objetivo entender a influência dessas ações de marketing nos hábitos de consumo desse público-alvo, ou seja, o fato de uma empresa apoiar a causa, tem relação com o desejo do consumidor em adquirir esse produto ou marca. A maioria dos respondentes entende essas ações como um diferencial, mas não necessariamente como um fator que implique em deixar de consumir outras marcas, visto que o fato de uma empresa não assumir uma posição é tido como aceitável pela maioria. Na questão seguinte, os entrevistados foram questionados diretamente a respeito das marcas que não assumem um posicionamento. Os respondentes endossaram a ideia que iriam continuar consumindo os produtos dessas empresas. Contudo, as organizações que apoiam o movimento teriam um peso maior na tomada de decisão. Isso ocorre porque os consumidores acabam se identificando e criando uma certa empatia pela empresa, assim gerando um diferencial para aqueles que se posicionam a favor.

A penúltima pergunta foi diretamente relacionada às empresas que assumem um posicionamento contra a comunidade LGBTQI+. De forma unânime, os entrevistados assumiram que deixariam de consumir as marcas. Nessa situação o consumo só iria ocorrer se caso não houvesse um substituto em nível de qualidade. Desse modo, é possível concluir que, quando as empresas não se posicionam, elas não são julgadas por isso, mas quando elas se envolvem com ações que vão em desencontro com a proposta da comunidade, ou até mesmo adotam um posicionamento de repúdio, os consumidores se sentem na obrigação de não adquirir mais. Por exemplo, o caso da loja da Riachuelo, que foi amplamente citado como um exemplo negativo de relacionamento com a comunidade LGBTQI+, conforme descrito anteriormente, a marca atualmente 
carrega uma imagem negativa dentro nesse segmento de mercado, por conta das declarações de Flavio Rocha, ex-presidente da empresa.

Nessas três questões é possível inferir o quanto a mudança no meio social, associado ao mundo globalizado influencia o relacionamento do consumidor com as marcas. As pessoas estão mais conscientes e atentas no que as organizações andam fazendo. Além disso, a troca de informações entre os membros dessa subcultura colabora para construção de uma interpretação sobre as ações de marca. Houve similaridade nas respostas obtidas a essas perguntas, onde as pessoas possuíam uma mesma visão e posicionamento. Desse modo, esse aspecto reforça que os indivíduos estão conscientes e seguro sobre os valores que sua causa carrega estão dispostos a zelar por isso. Como afirmado por Kotler e Keller (2017), a troca de informações entre os usuários possui um grande valor e transmite mais confiança sobre os produtos ou empresas.

\subsection{Descrição e análise dos resultados da segunda etapa de pesquisa}

A segunda etapa da pesquisa replicou o mesmo roteiro da etapa anterior, e buscou compreender a percepção de consumidores três meses depois das diversas ações de marketing que ocorreram em função durante o mês do orgulho LGBTQI+, em junho. Nessa etapa foi possível verificar se as respostas obtidas na primeira etapa se repetiam, além disso na segunda etapa a influência das datas comemorativas como dia dos namorados e mês do orgulho LGBTQI+, não interferem de forma tão forte como ocorreu na primeira pesquisa.

A primeira pergunta na entrevista buscou identificar quais ações de marketing com a temática LGBTQI+ que os consumidores se recordavam, novamente as iniciativas realizadas pelo Burger King voltaram a serem comentadas, o que reforça o quanto a marca está presente na memória desse consumidor. O entrevistado F2 destaca: "As ações do Burger King de colocar as coroas com o arco-íris no fim de semana da parada LGBTQI+ sempre me chamam atenção. Desde que eu vi que a empresa desenvolve ações como essa, passei a consumir mais". Além disso, a continuidade e consistência no desenvolvimento desse tema pela marca foi outro aspecto comentado pelos entrevistados, conforme destaca o F4: "[...] pois demonstra que eles lutam pela causa e estão abertos a qualquer tipo de clientela, não havendo discriminação".

Nesse aspecto é possível analisar a sensibilidade do consumidor com aspectos visuais, conforme destaca Solomon (2016), onde a percepção do cliente 
em relação a marca está associada a tradução das ações exercidas pelo marketing sensorial. Nesse caso relacionado ao desenvolvimento da visão, através do usa das cores que possuem um significado para o cliente LGBTQI+, assim criando uma aproximação. Vale ressaltar que as cores do arco-íris e a própria figura é um símbolo dessa subcultura.

Outra marca que voltou a ser bastante comentada foi O Boticário, novamente sendo citada pela campanha realizada no dia dos namorados. Desse modo, é possível interferir que esse posicionamento adotado pela empresa está associando a marca com a comunidade LGBTQI+, assim como ocorre com a Uber e Burger King.

A segunda pergunta feita aos entrevistados visava entender se eles achavam importante que marcas apoiassem a comunidade LGBTQI+. Mais uma vez, a visibilidade e representatividade foram bastante citadas como ponto forte do apoio feito pelas organizações - "as marcas têm papel fundamental na visibilidade da comunidade, e só sendo visto, que teremos mudanças, que as pessoas vão perceber que não há nada de errado ou que precisa ser mudado", entrevistado F2.

No atual cenário político, onde a causa LGBTQI+ está em situação desfavorável, em virtude das ideologias políticas da bancada que ocupa as principais cadeiras, além dos ideais políticos do atual presidente, é despertada na comunidade LGBTQI+ a necessidade de ganhar ou até manter o espaço que conquistou nos últimos anos. Desse modo, os entrevistados, ao citarem a representatividade e visibilidade concedida pelas marcas, destacaram esse sinal de reforço em seus valores e garantia de segurança em afirmarem o seu posicionamento na sociedade, diante de um ambiente de insegurança.

A terceira pergunta estava relacionada à interpretação que os consumidores dão às marcas que apoiam o movimento. Em relação à primeira etapa, a marca Riachuelo teve uma relevância maior, como um exemplo negativo pela a maioria dos entrevistados. Um outro ponto, é o objetivo das marcas estarem buscando faturar em cima dos consumidores, através da demonstração de apoio à causa, estando nítido para a maioria dos entrevistados. Contudo, os respondentes veem essa atitude de obter lucro através da comunidade, como um lado positivo, em função da visibilidade obtida para o grupo. Portanto, embora que o intuito seja financeiro, o modo como está sendo feito se torna mais aceitável - "isso não diminui a importância de tais publicidades dentro da sociedade atual, visto que a mídia exerce grande influência sobre o senso comum" entrevistado F14. 
O público LGBTQI+ demonstrou estar com um dilema entre as empresas que estão apoiando e a visibilidade que isso está trazendo. Embora as pessoas desaprovem o interesse comercial, elas acabam se conformando com essa situação, pois a visibilidade e representatividade que a comunidade LGBTQI+ está ganhando com isso, se torna um fator mais forte. Contudo, empresas que adotam essa postura podem ao longo prazo perder esse consumidor, uma vez que passado o "boom" da visibilidade, as empresas que são vistas como atuantes de forma mais consistente, como é o caso do Burger King, Uber e O Boticário, serão recordadas de forma positiva por esse público, enquanto outras podem sofrer uma evasão desses consumidores.

$\mathrm{Na}$ questão seguinte, os entrevistados foram questionados diretamente a respeito das marcas que não assumem um posicionamento. $O$ resultado se mostrou parecido com o da primeira etapa, onde os consumidores dizem não ver como um problema as empresas que não se posicionam, mas reforçam que aquelas que adotam medidas pró-comunidade acabam sendo mais recordadas e possuem um diferencial na hora da tomada de decisão. Além disso, nessa segunda fase os respondentes deram mais ênfase à valorização do seu públicoalvo, ou seja, o consumidor LGBTQI+ quer se sentir respeitado e incluído socialmente pelas marcas - "consumo mais Burger King hoje por causa das ações pró LGBTQI+. Também me considero fiel à Uber pelo mesmo motivo, mesmo sendo mais caro que a 99POP", entrevistado F3.

Uma outra perspectiva que surgiu diante dessa segunda etapa, está relacionada com os consumidores LGBTQI+ que se sentiram incluídos pelas marcas. De fato, nos últimos anos o número de empresas que vêm realizando ações de marketing direcionadas à comunidade sofreu um aumento expressivo, mas isso também pode estar sendo influenciado pelo fato de os consumidores estarem optando por empresas que realizam ações diretas para o grupo e, consequentemente não estão dando preferência para consumir naquelas que não se posicionam. Desse modo, algumas marcas parecem estar adotando um posicionamento mais superficial pró-LGBTQI+, em função de outras empresas estarem realizando esse tipo de associação. Logo, o interesse comercial na causa ganha força, pois não apoiar a causa pode estar significando uma perda de participação de mercado.

A penúltima pergunta é diretamente relacionada às empresas que assumem um posicionamento contra a comunidade LGBTQI+, e mais uma vez, de forma unânime, os entrevistados diziam que deixariam de consumir os produtos. 


\section{Conclusões e recomendações para novos estudos}

Esse trabalho pretendeu investigar a atitude e percepção do consumidor com relação ao posicionamento das marcas direcionado ao público LGBTQI+. O foco do estudo foi compreender como o consumidor interpreta a comunicação de algumas marcas ao demonstrar apoio à comunidade LGBTQI+ e quais empresas estão na memória de consumidores em relação ao tema. A questão se mostra importante na medida em que diversas organizações vêm direcionando ações de marketing e desenvolvendo produtos para esse grupo social.

Para atingir os objetivos pretendidos, realizou-se duas pesquisas de campo, em caráter qualitativo. Foram realizadas 30 entrevistas ao total, sendo 15 entrevistados em casa fase - a primeira fase ocorreu durante a Parada do Orgulho LGBTQI+ de 2019 em São Paulo, e a segunda fase ocorrendo três meses depois da primeira etapa.

Dentre as principais questões abordadas salientam-se a interpretação do consumidor e ações de marketing com direcionamento para o público LGBTQI+, que ficaram perpetuadas na memória do consumidor. Também se discutiu as perspectivas em torno de um posicionamento de marca consistente, onde empresas que buscam abraçar a causa LGBTQI+, possuem um interesse superior ao desejo de alcançar o "Pink Money".

O estudo constatou que as ações de marketing com constância e consistência fazem as marcas se tornarem referência para o mercado LGBTQI+. Empresas como Uber, Burger King e O Boticário, foram citadas pelos entrevistados como referência em relacionamento com essa subcultura. As três organizações adotam um posicionamento constante de apoio às minorias e buscam desenvolver a diversidade em suas ações publicitárias.

Um outro destaque obtido com o estudo se refere ao resultado das ações para desenvolvimento da diversidade no ambiente de trabalho e apoio a ONGs. Essas iniciativas, embora pareçam surtir pouca repercussão por estarem mais relacionadas com o ambiente interno, geram resposta na comunidade LGBTQI+, visto que esse público está bastante atendo às iniciativas organizacionais e o seu respectivo relacionamento com a comunidade. Além disso, esse segmento valoriza práticas que tragam benefícios para a comunidade. 
O estudo também traçou que o consumidor LGBTQI+ é um cliente como os demais, ou seja, gosta de ser valorizado e ter os seus valores respeitados. Desse modo, a apropriação dos símbolos e expressões das comunidades é utilizado pela maioria das organizações como forma de se identificar com esse público. Uma outra abordagem é a utilização do marketing de causa, como forma de desenvolver o tema da homossexualidade dentro da sociedade.

Uma outra perspectiva obtida com o estudo é em relação a visão que os clientes possuem diante de empresas que adotam a comunidade LGBTQI+ com fins lucrativos, sem demonstrar interesse em ajudar com a causa. Essa atitude gera uma imagem negativa para as marcas, contudo alguns consumidores aceitam esse meio de obter lucro, pois essas ações estão promovendo e gerando visibilidade para comunidade LGBTQI+, que não existia antes.

\subsection{Implicações gerenciais}

As organizações buscam se aproximar do cliente LGBTQl+ através dos símbolos e aspectos que pertencem a essa subcultura. Desse modo, são desenvolvidos produtos e peças publicitarias direcionadas a comunidade.

O presente estudo possibilitou entender que as empresas do segmento de vestuário brasileiro têm que repensar na forma como atua com a comunidade LGBTQI+, visto que esse segmento foi amplamente criticado pelo grupo respondente e associado como interesse comercial. Essa relação está relacionada à aplicação de símbolos dessa subcultura em roupas e acessórios, sem um propósito de gerar benefício para a comunidade LGBTQI+ com as vendas dos produtos.

O estudo identificou no consumidor, o desejo de proporcionar um retorno para a comunidade, com as vendas desses produtos que contém símbolos da comunidade LGBTQI+. Essa inferência pode ser percebida através das marcas mais citadas durante as entrevistas, onde elas são conhecidas por seu apoio a ONGs e desenvolvimento da diversidade em seu ambiente de trabalho.

Uma outra perspectiva é em relação a adoção de um posicionamento próLGBTQI+, onde se faz necessária uma análise da empresa em relação à sua imagem e valores transmitidos para os clientes. Essa atitude é importante para que a marca possa assumir esse posicionamento para o mercado caso decida fazê-lo. Ao verificar se existe um alinhamento interno com os princípios da comunidade, em especial a adoção de práticas voltadas para a diversidade, a empresa evitará se associar de forma negativa e gerar um efeito reverso. 
A presença de marcas na Parada do Orgulho LGBTQI+ não é o suficiente para que o consumidor associe a empresa com o movimento, é necessário a realização de ações constantes e bem consistentes. Iniciativas com essas características tendem a tornar as marcas mais conectadas ao mercado LGBTQI+.

\subsection{Sugestões e recomendações para novos estudos}

Como desdobramentos futuros, essa linha de estudo pode ser desenvolvida através de investigação sobre o retorno que as empresas então tendo ao desenvolverem coleções direcionadas a comunidade LGBTQI+, ou seja, buscar entender o outro lado desse presente estudo.

Na perspectiva de gerar mais conteúdo sobre a comunidade LGBTQI+, uma outra sugestão de estudo seria referente a uma análise mais profunda sobre o perfil do cliente LGBTQI+, de modo a auxiliar de forma mais eficaz o relacionamento das marcas com essa subcultura.

Uma outra sugestão de estudo, é referente ao tema marketing de causa, de modo a buscar trazer mais conteúdo sobre a percepção do consumidor e os benefícios que as organizações estão obtendo. Visto que se trata de uma abordagem mais recente, desse modo possuindo poucas informações referente ao tema. 


\section{Referências Bibliográficas}

ADNEWS. Burger King lança milk shake de unicórnio para celebrar
a diversidade. Exame. Disponível em:
<https://exame.abril.com.br/marketing/burger-king-lanca-milk-shake-de-
unicornio-para-celebrar-a-diversidade/> Acesso em: 20 de junho de 2019 .

BURGUER KING. Página Oficial da coleção BURGER KING Pride, 2019. <https://www.bk.com/diversity>. Acesso em: 10 de outubro de 2019.

CHURCHILL, G.A. \& PETER, J. Marketing: Criando Valor para o Cliente. São Paulo: Ed. Saraiva, 2012.

DEARO, Guilherme. Burger King traz drag queen para campanha. Exame. Disponível em: <https://exame.abril.com.br/marketing/burger-king-traz-drag-queen-campanha/> Acesso em: 20 de junho de 2019.

GIL, A.C. Métodos e técnicas de pesquisa social. [s.I.]: Atlas, 2010.

KEVIN L. KELLER \& PHILIP KOTLER: Administração de Marketing. São Paulo: Ed. Pearson, 2012.

KOTLER, P., KARTAJAYA, H., SETIWAN, I..Marketing 4.0: do tradicional ao digital. Rio de Janeiro: Sextante, 2017.

MCCRACKEN, Grant. Cultura e consumo. Mauad Editora Ltda, 2003

MARROQUÍN, J. Carlos. Novo consumidor mais informado, mais exigente, mais consciente. Exame. Disponível em:

<https://www1.folha.uol.com.br/topofmind/2014/10/1528719-novo-consumidormais-informado-mais-exigente-mais-consciente.shtml> Acesso em: 22 de junho de 2019.

NUNAN, Adriana. Homossexualidade: do preconceito aos padrões de consumo. Caravansarai, 2003.

PARADA LGBT DE SP VAI PARA O 'GUINNESS. Memorial da Democracia, São Paulo, 26 de outubro de 2006. <http://memorialdademocracia.com.br/card/paradalgbt-de-sp-no-guiness-book> Acesso em: 20 de junho de 2019.

PINHONI, Marina. Parada LGBT de 2019 movimentou R\$ 403 milhões em SP, diz prefeitura G1, São Paulo. Disponível em: $<$ https://g1.globo.com/sp/sao-paulo/noticia/2019/06/29/23a-parada-lgbtmovimentou-r-403-milhoes-em-sao-paulo-diz-prefeitura.ghtml > Acesso em: 20 de junho de 2019. 
Potencial do mercado homossexual no Brasil. Mundo do Marketing.

Disponível em:

$<$ https://www.mundodomarketing.com.br/inteligencia/estudos/298/potencial-domercado-homossexual-no-brasil.html>. Acesso em: 14 de maio de 2019.

Propaganda de 0 Boticário com casais gays vence prêmio publicitário. G1, São Paulo, 20 de outubro de 2015. Disponível em:

$<$ http://g1.globo.com/economia/midia-e-marketing/noticia/2015/10/propagandada-boticario-com-casais-gays-vence-premio-publicitario.html>. Acesso em: 14 de maio de 2019.

RIACHUELO. Página Oficial da coleção Riachuelo Pride, 2019.

<https://www.riachuelo.com.br/pride>. Acesso em: 10 de outubro de 2019.

RIES, A. \& TROUT, J.Positioning: the batlle for your min. Nova York: $20^{\circ}$ Ed. de aniversário: McGraw-Hill, 2000.

SANTOS, Deborá. Casais gays ganham mais que casais heterossexuais, mostra IBGE.

G1, São Paulo. Disponível em:

<http://g1.globo.com/brasil/noticia/2011/11/casais-gays-ganham-mais-quecasais-heterossexuais-mostra-ibge.html/> Acesso em: 20 de junho de 2019.

SCRIVANO, Roberta. Potencial de compras LGBT é estimado em R\$ 419 bilhões no Brasil. O GLOBO, 05 de abril de 2015. Disponível em:

$<$ https://oglobo.globo.com/economia/potencial-de-compras-lgbt-estimado-em419-bilhoes-no-brasil-15785227> Acesso em: 13 de maio de 2019

SOLOMON, MICHAEL R.: O comportamento do Consumidor. São Paulo: Ed. Bookman, 2009.

SOLOMON, MICHAEL R.: O comportamento do Consumidor. São Paulo: Ed. Bookman, 2016. 


\section{Anexo 1}
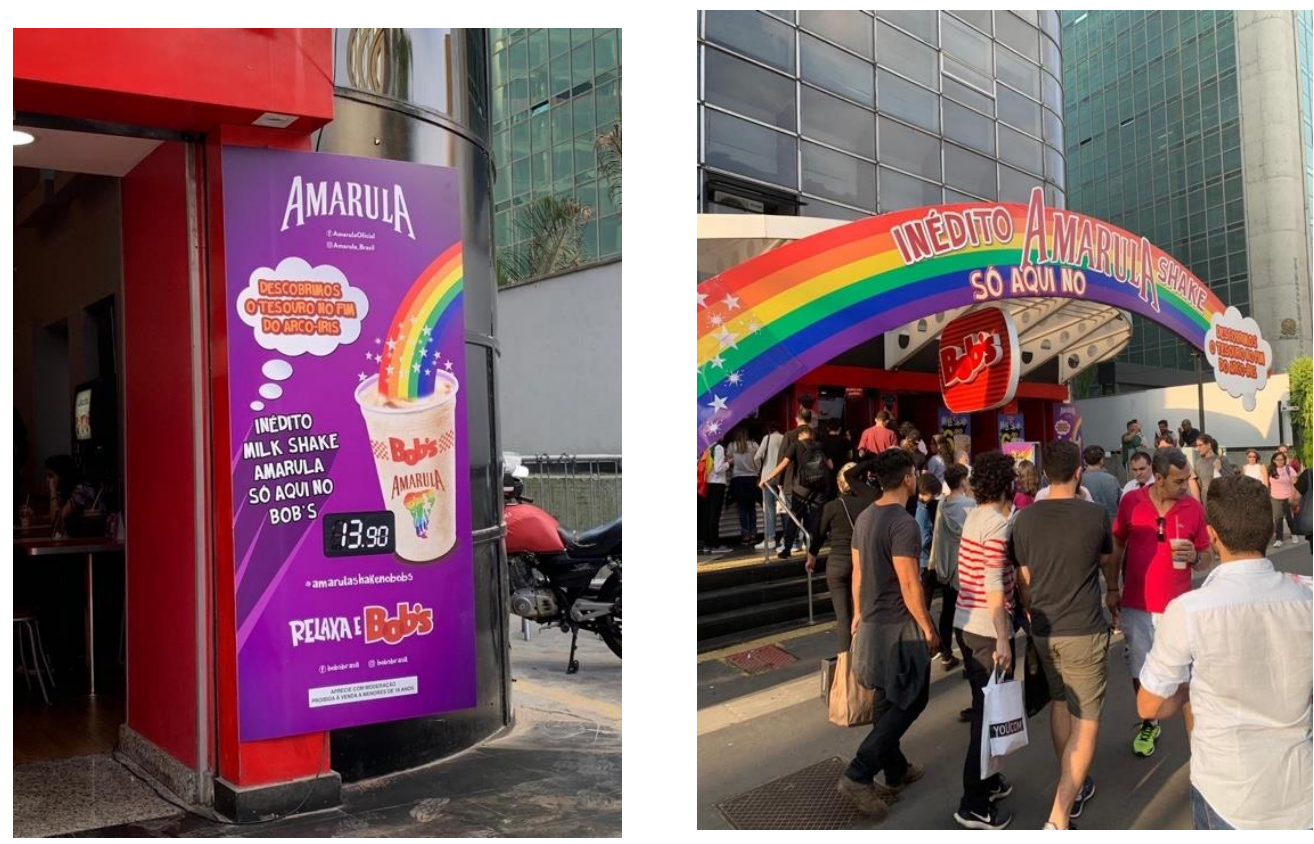

Imaqem 1 e 2: Acão de marca do BOB's para a Parada do Oraulho LGBTQI+ de São Paulo.
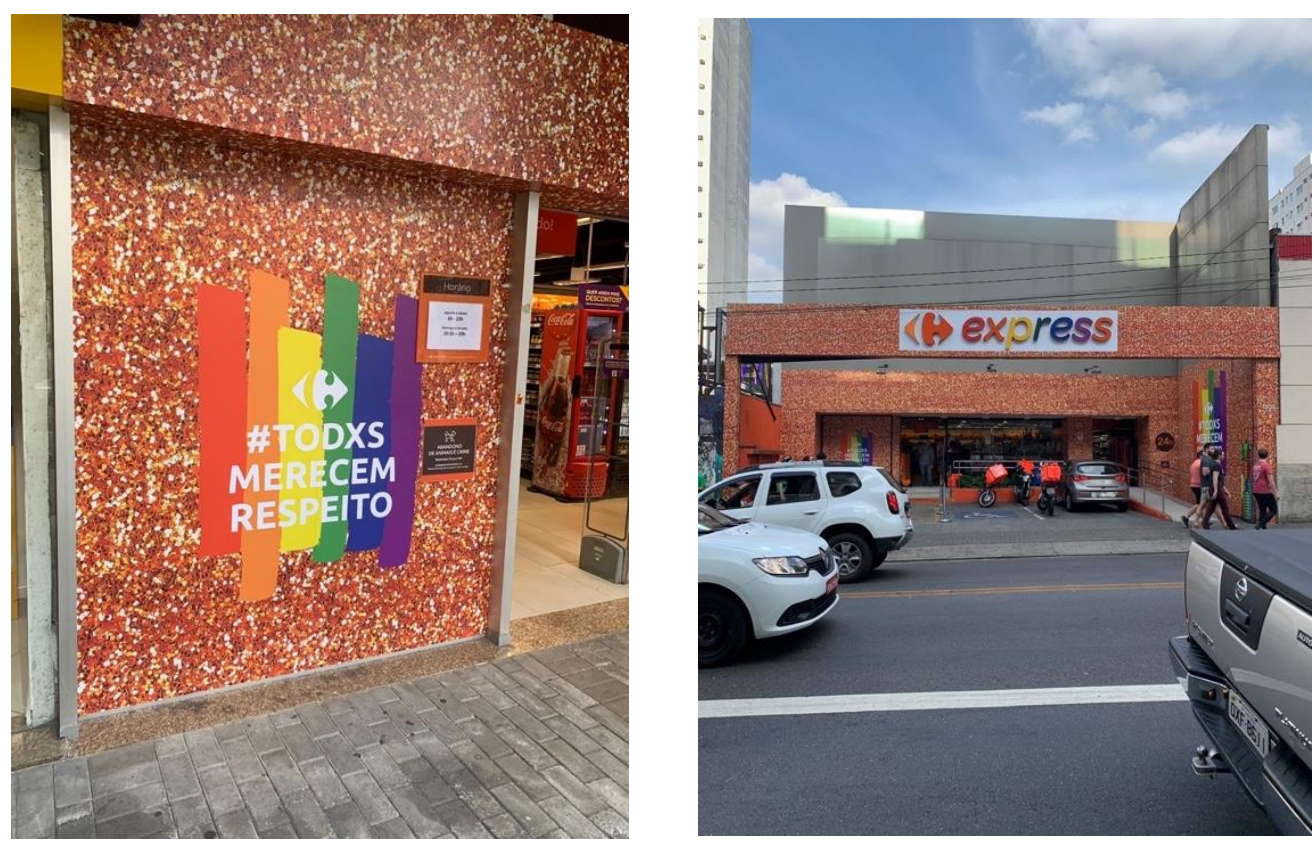

Imagem 3 e 4: Ação de marca do Carrefour para a Parada do Orgulho LGBTQI+ de São Paulo, 2019. 

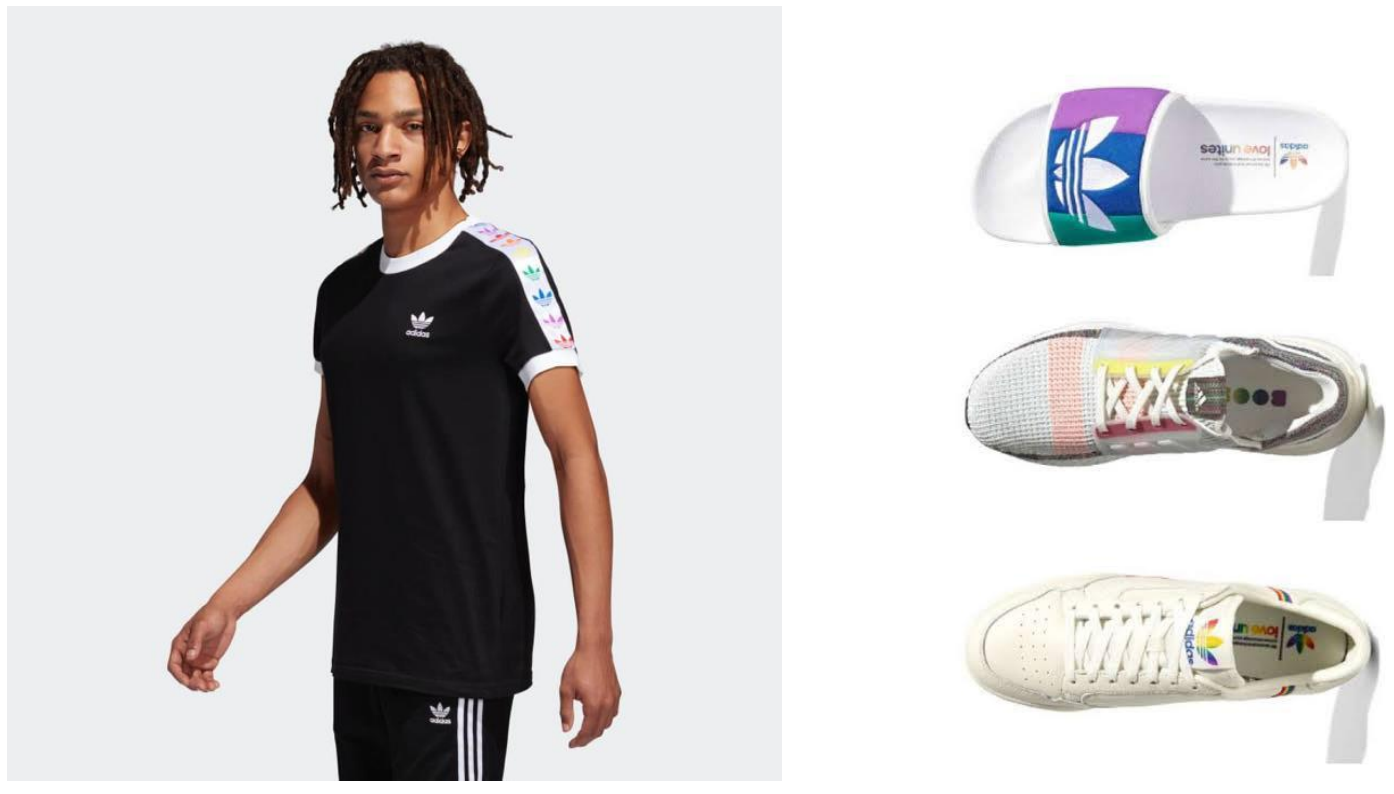

Imagem 5 e 6: Coleção Adidas Pride - 2018

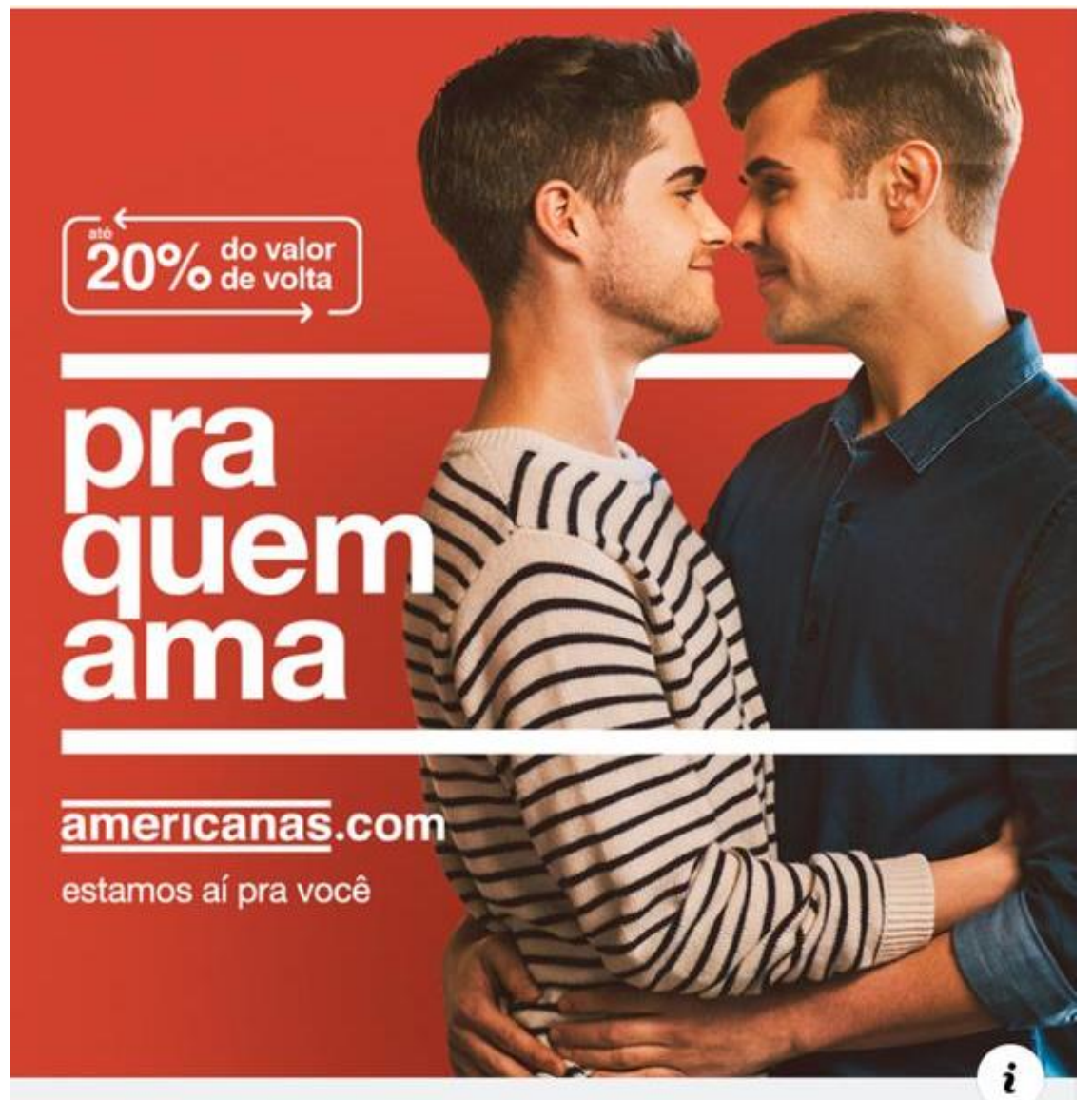

AMERICANAS.COM

Estamos aí pra você no Dia dos

Namorados :) nas Lojas Americanas.c...

Imagem 7: Campanha do dia dos namorados, Americanas.com, 2019. 


\section{Anexo 2}

\section{Perguntas realizadas na primeira fase:}

1 - Você se recorda de alguma propaganda com temática LGBTQI+?

2 - Você acha que é importante marcas apoiarem a comunidade LGBTQI+?

3 - Você acha que as marcas apoiam o movimento por interesse próprio ou por interesse na causa LGBTQI+? Consegue citar algum exemplo?

4 - Você acredita que seus hábitos de consumo vão mudar em relação as marcas que estão se envolvendo com a causa?

5 - Se alguma dessas marcas não tivessem demonstrado apoio a comunidade, isso faria alguma diferença na sua tomada de decisão?

6 - Mas se elas estivessem se mostrado contra a comunidade LGBTQI+?

7 - Quais marcas você acha que tem um maior envolvimento com o público LGBTQI+?

\section{Perguntas realizadas na segunda fase:}

1 - Você se recorda de alguma propaganda ou ação de marketing com temática LGBTQI+? O que você achou dela? Essa propaganda mudou em algo sua opinião sobre a marca? (Se sim, de que forma?)

2 - Você acha que é importante marcas apoiarem a comunidade LGBTQI+?

3 - Você acredita que seus hábitos de consumo vão mudar em relação as marcas que estão se envolvendo com a causa?

4 - Se alguma dessas marcas não tivessem demonstrado apoio a comunidade, isso faria alguma diferença na sua tomada de decisão? 5 - Mas se elas estivessem se mostrado contra a comunidade LGBTQI+? 6 - Quais marcas você acha que tem um maior envolvimento com o público LGBTQI+? 


\section{Anexo 3}
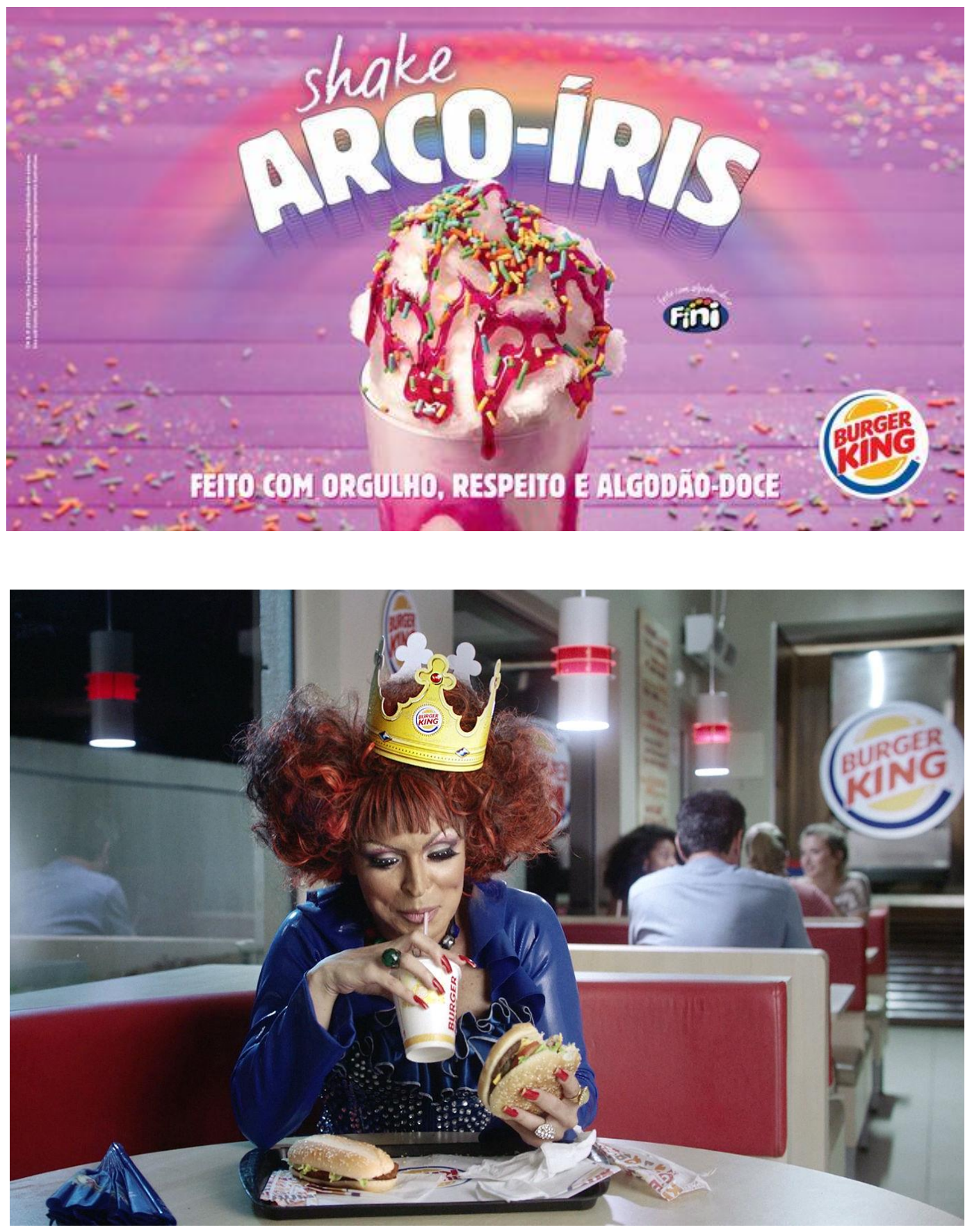

Imagem 8 e 9: Ações de marca do Burger King 


\section{Anexo 4}
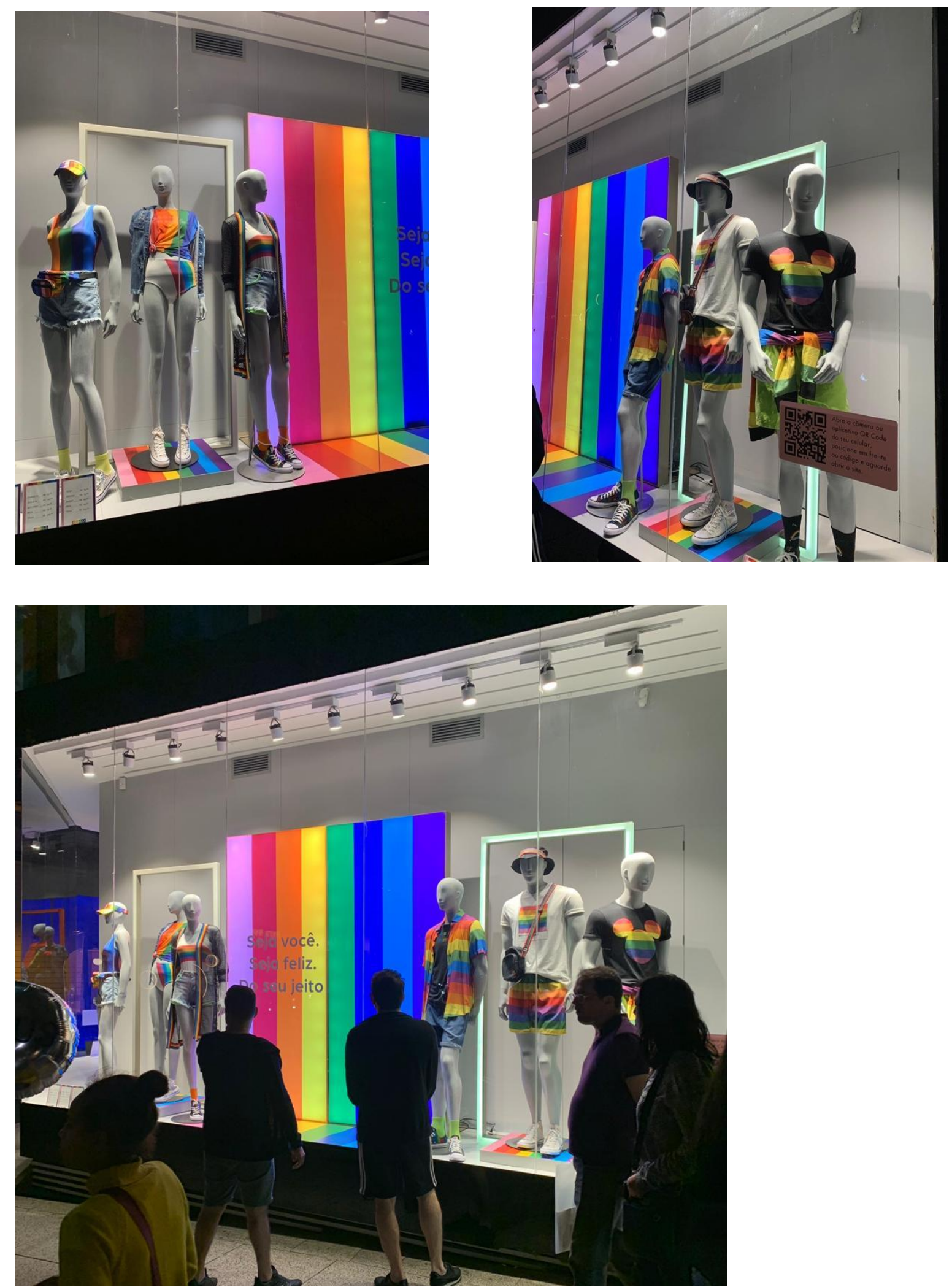

Imagem 10, 11 e 12: Ações de marca da Loja Riachuelo, para o mês do orgulho LGBTQI+ 2019. 